\title{
EFEITOS DA APLICAÇ̃̃O DE CALCÁRIO CALCINADO, GESSO E MISTURAS DE CALCARIO DOLOMITICO CALCINADO E GESSO EM CULTURAS DE INTERESSE ECONÔMICO
}

\author{
MANOEL RAIMUNDO GUILHERME \\ Engenheiro Agrônomo
}

Orientador: EURIPEDES MALAVOLTA

Dissertação apresentada à Escola Superior de Agricultura "Luiz de Queiroz", da Universidade de São Paulo, para obtenção do título de Mestre em Agronomia, Área de Concentração: Solos e Nutrição de Plantas.

$$
\begin{gathered}
\text { PIR A C IC A B A } \\
\text { Estado de São Paulo - Brasil } \\
\text { Dezembro }-1986
\end{gathered}
$$


ii.

Aos meus pais,

OFEREÇO.

A. minha esposa

e giehos

DEDICO. 


\section{HOMENAGEM}

A Escola Superior de Agricultura "Luiz de Queiroz" - USP, Pi racicaba (SP) ;

Ao Centro de Energia Nuclear na Agricultura (CENA) - USP, Piracicaba (SP);

Ao Conselho Nacional de Desenvolvimento Cientifico e Tecnológico (CNPq);

A Indüstria Mineradora Pagliato Ltda, Sorocaba(SP);

.. por tornarem possível a realização do presente traba1ho.

\section{HOMENAGEM POSTUMA}

Ao amigo e colega Engo Agro Raimundo Marques Carneiro. 


\section{AGRADECIMENTOS}

Ao Prof. EURIPEDES MALAVOLTA pela orientação, estímulo e com preensão;

Ao Prof. GODOFREDO CESAR VITTI pela valiosa colaboração, estímulo e sobretudo amizade;

Aos Professores GERALDO VICTORINO DE FRANÇA, HENRIQUE PAULO HAAG, FRANCISCO ASSIS FERRAZ DE MELLO \& MOACYR OLIVEIRA CAMPONEZ DO BRASIL SOBRINHO pelas manifestações de companheirismo, confiança e apreço;

AO PAULO SALVADOR DE ALMEIDA pelo incentivo e colaboração;

AO LAURY SOUTO DE QUEIROZ e AYRTON NEGREIROS COELHO pela colaboração e sobretudo dedicação na condução dos ensaios;

AO CLAUDIO DE JESUS MONTEIRO, ANTONIO RODRIGUES DOS SANTOS, MARCOS GARIBALDI E VINICIUS FERRAZ pela valiosa colabora ção:

Às funcionärias do Departamento de Química da ESALQ: LOCIA HELENA APESSATO PAVAN, LURDES APARECIDA DARIO DE GONZALEZ e SUELI MARIA AMARAL CAMPOS pela valiosa colaboração: 
$\bar{A}$ CLEUSA PEREIRA CABRAL e LIGIA MALAVOLTA pela valiosa cola boração;

Ãs funcionārias da SEÇÃO DE PÓS-GRADUAÇÃO DA ESALQ: Dirce Alessi Pelegrino, Luzia Arana Soares, Edilma Aparecida Bue no de Camargo Ortolan, Silvia Denise de Freitas Siqueira, Celine Coppê de Souza, Maria Helena da Silva Maia, Stela Aparecida Alessi e Marisa Rodrigues de Camargo Duarte pela amizade e compreensão.

A todos que, direta ou indiretamente, colaboraram para a realização deste trabalho. 
vi.

\section{INDICE}

Pāgina

RESUMO

ix

SUMMARY

$\mathrm{xi}$

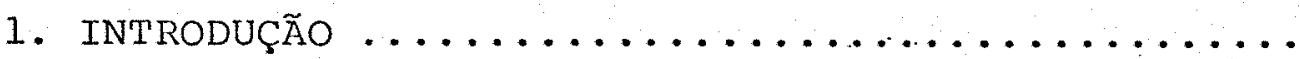

01

2. REVISÃO DE LITERATURA ................... 04

2.1. Aspectos Gerais ............... 04

2.2. Gesso Agricola .................. 07

2.2.1. Caracterização $\ldots \ldots \ldots \ldots \ldots \ldots \ldots .07$

2.2.2. Uso do gesso como fonte de enxofre e como corretivo do alumínio do subsolo $\ldots \ldots \ldots \ldots \ldots \ldots \ldots \ldots \ldots \ldots$

2.3. Ensaios com calcário e gesso aplicados sepa radamente

2.4. Ensaios com calcário e gesso aplicados con juntamente $\ldots \ldots \ldots \ldots \ldots \ldots \ldots \ldots \ldots \ldots$

3. MATERIAL E METODOS $\ldots \ldots \ldots \ldots \ldots \ldots \ldots \ldots \ldots \ldots$

3.1. Local de condução dos ensaios $\ldots \ldots \ldots \ldots \ldots .17$

3.2. Ensaios em casa-de-vegetação ........... 17

3.2.1. Delineamento estatistico ....... 17

3.2.2. Solos $\ldots \ldots \ldots \ldots \ldots \ldots \ldots \ldots \ldots \ldots, 18$

3.2.3. Cultivar utilizado ............ 18 
vii.

Pāgina

3.2.4. Recipientes ................. 18

3.2.5. Material corretivo ............ 18

3.2.6. Metodologia seguida ............ 19

3.2.6.1. Coleta e preparo dos solos. 19

3.2.6.2. Incubação dos solos $\ldots \ldots .20$

3.2.6.3. Adubação bāsica ....... 20

3.2 .6 .4 . Semeadura ............ 23

3.2 .6 .5 . Condução dos ensaios $\ldots \ldots 24$

3.3. Ensaios de campo ................ 25

3.3.1. Delineamento estatístico $\ldots \ldots \ldots 25$

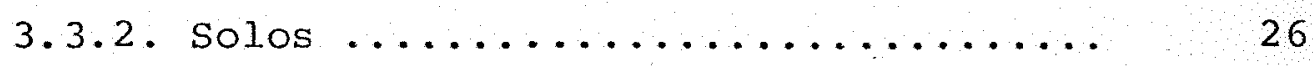

3.3.3. Amostragem dos solos e análise quími

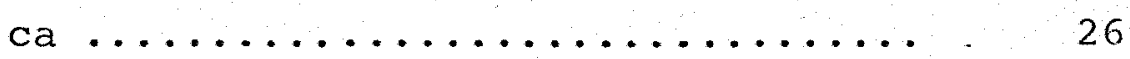

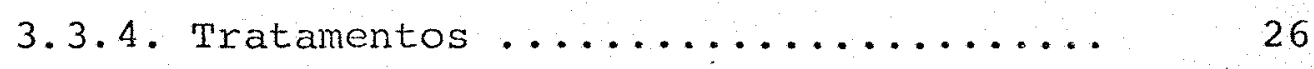

3.3.5. Culturas utilizadas .......... 28

3.3.6. Instalạ̧ão dos ensaios .......... 29

3.3.7. Semeadura e adubação ............ 29

3.3.8. Condução dos ensaios $\ldots \ldots \ldots \ldots \ldots \ldots . . .30$

3.3.8.1. Desbaste e adubação em cobertura .............. 30

3.3 .8 .2 . Tratos culturais ........ 31

3.3.9. Cultivo do trigo em sucessão à soja. 31

3.3.10. Colheita dos ensaios .......... 31

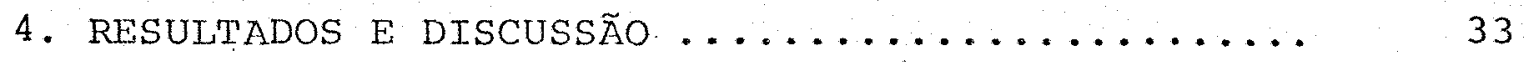


viii.

Página

4.1. Ensaios em casa-de-vegetação .......... 33

4.2. Ensaios de campo ................ 40

5. CONCLUSÕES $\ldots \ldots \ldots \ldots \ldots \ldots \ldots \ldots \ldots \ldots \ldots \ldots \ldots$

6. IITERATURA CITADA $\ldots \ldots \ldots \ldots \ldots \ldots \ldots \ldots \ldots \ldots \ldots \ldots \ldots \ldots$ 


\title{
EFEITOS DA APLICACֵÃO DE CALCÁRIO CALCINADO, GESSO E MISTURAS DE CALCARIO DOLOMITICO CALCINADO E GESSO EM CULTURAS DE INTERESSE ECONÔMICO
}

\author{
Autor: MANOEL RAIMUNDO GUILHERME \\ Orientador: Prof. Dr. EURIPEDES MAIAVOLTA
}

\section{RESUMO}

o presente trabalho visou estudar, em condições de casa-de-vegetação e de campo, a eficiência agronômi ca de misturas de calcário dolomítico calcinado e gesso agrícola em comparação com cada um dos dois produtos aplicados se paradamente. Para tal, foram usados solos ácidos com diferen tes características químicas a saber: Um Podzólico vermelho Ana relo (PVA) de Capão Bonito (SP); um Latossolo Vermelho Escuro textura média (LEm) de Sorocaba (SP); um Latossolo Roxo (LR) de Itapeva (SP). Sob condições de casa-de-vegetação a planta teste foi milho, enquanto que no campo foram usadas milho, soja e trigo. As misturas de calcário dolomítico calcinado e gesso agrícola foram feitas nas proporções de 70\%:30\% e $90 \%: 10 \%$, respectivamente. Os tratamentos adicionais foram: testemunhá, calcário dolomítico calcinado e gesso. o calcārio dolomítico calcinado e as misturas foran aplicados em quan tidades calculadas para elevar o $\mathrm{pH}$ (água) para 6,5 ou a satu ração em bases (Vo) para $70 \%$, respectivamente, para os experí mentos em casa-de-vegetação e campo. As doses de gesso agrícola foram estimadas para suprir as mesmas quantidades de CaO 
aplicadas como calcário dolomítico calcinado quando ele foi usado separadamente. Os dados obtidos permitem tirar as seguintes conclusões:

a) As misturas de calcário dolomítico calcina do e gesso deram maior produção de matēria seca ou grãos, quan do comparados com cada um dos produtos aplicados separadamente;

b) a mistura 70\%:30\% demonstrou ser superior à mistura $90 \%$ : 10\%;

c) de um modo geral, as produçôes foram concordantes, obedecendo os tratamentos a seguinte ordem decrescente: mistura 70\%:30\% > mistura 90\%:10\% > calcário dolomítiGo calcinado > gesso > testemunha;

d) as anālises minerais realizadas na parte aé rea das plantas de milho, cultivadas em vasos, mostraram que o calcărio dolomítico calcinado e as misturas reduziram as concentrações de Al e Mn na matêria seca; o gesso quando usado separadamente promoveu um aumento na concentração de $\mathrm{Mn}$; por outro lado, o calcário dolomítico calcinado e as misturas aumentaram a concentração de $\mathrm{Ca}, \mathrm{e}$, particularmente, de Mg no tecido; sempre que o gesso esteve presente houve aumento nos teores de $\mathrm{Ca}$ e $\mathrm{s}$. 


\title{
EFFECTS OF THE APPLICATION OF CALCINED LIMESTONE, PHOSPHOGYPSUM AND BLENDS OF CALCINED DOLOMITIC LIMESTONE AND PHOSPHOGYPSUM AND CROPS OF ECONOMIC INTEREST
}

\author{
Author: MANOEL RAIMUNDO GUILHERME \\ Adviser: Prof. Dr. EURIPEDES MALAVOLTA
}

\section{SUMMARY}

The present work aimed to study, both in the greenhouse and in the field, the agronomic efficiency of blends of calcined dolomitic limestone and phosphogypsum in comparison with each of the two products applied separately. In order to do so acid soils with different chemical characteristics were used namely: a Red Yellow Podzolic (PVA) from Capão Bonito (SP); a Dark Red Latosol (LEm) from Sorocaba, SP; a Roxo Latosol (LR) from Itapeva (SP). Under greenhouse conditions corn was the test plant, whereas in the field corn, soybean and wheat were used. The calcined dolomitic limestone phosphogypsum blends. were made in the proportions of $70 \%: 30 \%$ and $90 \%: 10 \%$, respectively. Additional treatments were: control, calcined dolomitic limestone, and phosphogypsum. Calcined dolomitic limestone and blends were applied in rates calculated to raise the $\mathrm{pH}$ (water) to 6.5 or the base saturation (Vo) to $70 \%$, respectively, for greenhouse and field experiments. Phosphogypsum rates were estimated to supply the same CaO quantities applied as calcined dolomitic limestone when it was used separately. 
Data obtained allowed for the following conclusions to be drawm: a) The calcined dolomitic limestone and phosphogypsum blends have higher dry matter or grain yields when compared to each product separately applied. The 70\%:30\% blend proved to be better than the 90\%:10\% mixture. c) As a rule, insofar yields were concerned, the treatments obeyed the following decreasing order: $70 \%: 30 \%$ blend $>90 \%: 10 \%$ blend > calcined dolomitic limestone > phosphogypsum > control. d) Mineral analyses carried out in the tops of the corn plants grown in pots showed that calcined limestone and blends there of reduced both $\mathrm{Al}$ and Mn concentration in the dry matter; phosphogypsum when used separately promoted an increase in Mn concentration. On the other hand, calcined dolomitic limestone and blends increased Ca, and particularly Mg concentration in the tissue; whenever phosphogypsum was present there were increases both in $\mathrm{Ca}$ and $\mathrm{S}$. 


\section{INTRODUC,ÃO}

o aumento da área cultivada, seja pela necessi dade de maior demanda de alimentos, busca de fontes alternati vas de energia e obtenção de excedentes exportáveis, tem leva do à utilização, cada vez mais frequente, de áreas antes consideradas marginais por problemas de fertilidade.

Neste contexto, destacam-se as áreas sob vegetação de cerrado, que representam cerca de 87 milhões de hectares agricultáveis. Nessa região, predominam os Latossolos, apresentando deficiência generalizada de nutrientes, acidez elevada com alta saturação por alumínio, principalmente nas camadas subsuperficiais.

Situação semelhante já está sendo observada na grande maioria das äreas tradicionalmente cultivadas no país. Essas caracteristicas limitam o desenvolvimento e produção das culturas, quer por reduzir o crescimento do sistema radicular, tornando-as mais susceptiveis a déficits hîdricos, quer por interferir na absorção e transporte de nutrientes, contribuindo ademais para a fixação do fósforo no solo. 
Vārias alternativas tem sido propostas e estudadas para a utilização racional desses solos, a saber: 1) se leção de espécies e variedades tolerantes a altas saturações de alumínio no subsolo; 2) incorporação profunda de calcário. Embora esta última alternativa resulte em produtividades mais elevadas do que as obtidas com a aplicação superficial do calcário $(0-20 \mathrm{~cm})$, ela é muito dificil, ou mes mo, agronômica e economicamente inexequivel. Isso se explica, considerando-se os seguintes aspectos: 1) falta de equipamen tos apropriados; 2) alto consumo de energia; 3) existência de extensas āreas apresentando esse problema no subsolo.

Atualmente, a pesquisa tem procurado meios efi cientes para minimizar o problema do aluminio tóxico na subsuperfície, com a elevação dos teores de cálcio, sem a incorporação profunda de calcário.

Apesar do movimento de bases para as camadas inferiores ser considerado prejudicial nos oxissolos, a lixiviação de cálcio pode ser considerada como importante instrumento para promover o aprofundamento das raízes. Esse efeito pode ser obtido com a aplicação do gesso agrícola, devido a sua solubilidade no solo e a presença do ín $\mathrm{SO}_{4}^{-2}$ associado a $\mathrm{Ca}^{+2}$, que desce com relativa facilidade no perfil do solo, che gando a profundidades que não são usualmente atingidos pelos calcários. Entretanto, o uso do gesso isoladamente pode promover, tambēm, a lixiviação de $\mathrm{K}^{+}$e $\mathrm{Mg}^{+2}$, em solos ācidos e de baixa CTC. 
Assim sendo, a prática mais apropriada para o manejo de solos nessas condições, parece ser a combinação de gesso com calcārio, de preferência o dolomítico.

Portanto, pode-se considerar dois modos de aplicação desses "produtos", a saber: 1) Aplicação do calcário e em seguida o gẹsso; 2) Aplicação simultânea da mistura de calcário e gesso.

A segunda alternativa parece ser a mais promis sora, pois apresenta as seguintes vantagens: 1) melhora as propriedades físicas do gesso; 2) permite a comercialização do gesso pelas empresas produtoras de calcário; 3) a quantidade a aplicar é calculada de acordo com a necessidade de calagem do solo e 4) os produtos săo aplicados numa única operação.

Por outro lado, a. carência de enxofre que aparece com exequência cada vez maior, praticamente en todos os estados da Federação, é particularmente acentuada nos Estados de São Paulo, Minas Gerais, Mato Grosso do sul, Paraná e Rio Grande do sul. Conforme se pode observar, em 42.252 amostras analisadas no período de $1984 / 86$ (Laboratório da Indüstria Mi nerado Pagliato Ltda, Sorocaba, SP), 66,5\% dos solos cultivados do pais apresentaram teores de $\mathrm{S}^{-\mathrm{SO}_{4}^{-2}}$ entre "muito baixo" e "baixo" $\left(0-10 \mu \mathrm{g} / \mathrm{cm}^{3}\right)$.

Em vista dos motivos expostos, o objetivo do presente trabalho foi estudar a eficiẽncia agronômica de misturas de calcário dolomitico calcinado e gesso agrícola, em condições de casa-de-vegetação e campo. 


\section{REVISÃO DE LITERATURA}

\subsection{Aspectos Gerais}

Os solos tropicais săo normalmente ăcidos, seja pela ocorrência de precipitação suficientemente alta para lixiviar quantidades apreciáveis de bases trocāveis, seja pela ausência de minerais primārios e secundārios responsāveis pela reposição das mesmas (VITTI, 1984). Além da ocorrência natural de acidez do solo, pelos motivos acima expostos, o próprio cultivo tende a acentuar o problema, seja devido a ab sorção de cátions pelas raizes das plantas, deixando em seus lugares quantidades equivalentes de ions hidrogênio, bem como por prăticas agrïcolas, como a aplicação de fertilizantes nitrogenados acidificantes (sulfato de amônio, uréia, nitrato de amônio, fosfatos de amônio, etc.) ao solo (VITTI e FERREIRA, 1986). Asșim sendo, a acidificação do solo ē um processo inevitável, exigindo, portanto, correções periódicas do mesmo pela aplicação de materiais corretivos, para que se não limite a produção agrícola. 
Alēm desse aspecto, è importante salientar que, até o momento, a grande maioria das pesquisas têm-se referido ao estudo da correção da acidez na camada arável do solo, ficando a descoberto, quase por completo, os efeitos prejudiciais do aluminio presente nos horizontes subsuperficiais, pois, - mesmo restringindo o desenvolvimento radicular das culturas nessas camadas, é um obstáculo à maximização das produções, porque o volume de solo explorado pelas raizes é insuficiente para suprir as necessidades de ägua e nutrientes da planta (OLMOS \& CAMARGO, 1976).

Além da presença do aluminio, o aprofundamento do sistema radicular pode também ser impedido por níveis baixos de cálcio no subsolo (PAVAN, 1986).

A calagem, termo empregado na agricultura para designar a aplicação de material corretivo (predominantemente calcários), capaz de reduzir a acidez do solo, tem por finali dade três objetivos principais: correção da acidez e aumento na disponibilidade de nutrientes, que tem o seu máximo na fai xa de pH $6,0-6,5$; fornecimento dé cálcio e magnésio; neutraIização do excesso de Al e $M n$ e, consequente, diminuição na sua participação na CTC (MALAVOLTA et alii, 1986).

Devido ao ín acompanhante do $\mathrm{Ca} e$ do $\mathrm{Mg}$ nos corretivos, ser o carbonato $\left(\mathrm{CO}_{3}^{2-}\right)$, a calagem atinge os benefícios citados, de modo apreciável, nas camadas superficiais do solo; exceção feita quando são usadas doses relativamente pesadas de corretivos em solos bem estruturados e quanto hä 
tempo suficiente (QUAGGIO et alii, 1981). Consequência: pode-se ter solo corrigido pela calagem até no máximo $30 \mathrm{~cm}$, e solo não corrigido logo abaixo, prejudicando o desenvolvimento do sistema radicular e o aproveitamento do adubo aplicado. Colorário: plantas menos desenvolvidas e menos produtivas, mais sujeitas à seca (MALAVOLTA et alii, 1986).

Além do problema de toxidez de alumínio e dos baixos níveis de cálcio do sub-solo; o teor de nutrientes dos oxissolos e ultissolos é bastante baixo. Dentre os nutrientes, a deficiência de enxofre (S) atinge 50\% da área total dos solos da América Tropical (SANCHEZ \& SALINAS, 1981). Esse fato já havia sido alertado há muito tempo por McCLUNG etalii (1959), os quais verificaram que quando o enxofre rião foi aplicado em solos do planalto central brasileiro, o crescimento das plantas foi de apenas 4 a $30 \%$ do obtido guando um fextilizante completo foi aplicado. Assim, não è surpresa, que concomitantemente com o aumento da produção nos trópicos, há tambēm um aumento, comprovado de deficiência desse elemento (BLAIR, 1979). As duas razões mais importantes para explicar tal fato são: a) Nos solos das regiões tropicais as quantida des de $S$ no perfil, explorado pelas raízes das plantas, são frequentemente mais baixas quando comparadas às das regiões temperadas; b) Aumento considerável no uso de adubos simples e de förmulas de fertilizantes "concentradas", com pouco ou nenhum enxofre (VITTI, 1986).

Sendo assim, o emprego do gesso agrícola, 
qual promove o enriquecimento do perfil do solo em cálcio, com consequente diminuição da saturação em alumínio, bem como o fornecimento de enxofre, associado aos efeitos benéficos do calcário na camada superficial do solo, parece ser o ponto de partida para que seja atingido o potencial total do moderno sistema de agricultura nos países tropicais.

\section{2, Gesso Agricola}

\subsubsection{Caracterização}

o gesso agricola, suifato de cälcio dihidratado $\mathrm{CaSO}_{4} \cdot 2 \mathrm{H}_{2} \mathrm{O}$, é um subproduto da obtenção do ácido fosfórico, utilizado na fabricação de superfosfato triplo e fosfatos de amônio (MAP e DAP). Em média, para cada tonelada de $\mathrm{P}_{2} \mathrm{O}_{5}$ produzida se tem 4,5 toneladas desse sub-produto. Assim, o gesso não incorporado nesses adubos " concentrados", jä represen ta atualmente um volume de cerca de 20 milhões de toneladas, - que corresponde a 3,2 milhões de toneladas de enxofre (S). Considerando-se o preço de 150 dólares/tonelada de $S$, verifica-se que o valor desse elemento acumulado no gesso atinge a cifra de 480 milhões de dólares (VITTI et alii, 1986).

Esse gesso apresenta-se na forma de pó branco, revelando em sua composição aproximadamente $28 \%$ CaO e 17\% S, bem como uma solubilidade muito maior do que a do calcário 
(VITTI et alii, 1986). Essas características associadas à sua elevada disponibilidade no mercado, tornam o gesso agrícola uma das alternativas mais promissoras, principalmente, como fonte de enxofre e como "corretivo" do aluminio subsuperficial.

\subsubsection{Uso do gesso como fonte de enxofre e como corretivo do aluminio do subsolo}

Os efeitos favoráveis do emprego do gesso como fonte de enxofre foram amplamente discutidos em VITTI \& MALAVOLTA (1985) e VITTI et alii (1986). Analisando-se estes tra balhos, observa-se que teores médios de cerca de $30 \mathrm{~kg} / \mathrm{ha}$ de $S(200 \mathrm{~kg} / \mathrm{ha}$ de gesso) foram suficientes para promover a máxi ma produção das culturas testadas, fossem anuais ou perenes (cafē).

Com relação ao emprego do gesso como "corretivo" do aluminio subsuperficial, os primeiros trabalhos foram feitos por REEVE \& SUMNER (1972), em oxiśsolos da Africa do Sul, os quais compararam a eficiencia do $\mathrm{Ca}(\mathrm{OH})_{2}$ e do $\mathrm{CaSO}_{4}$. $2 \mathrm{H}_{2} \mathrm{O}$ na redução da saturação de $\mathrm{Al}$ no subsolo, tendo verifica do que, enquanto $\mathrm{O} \mathrm{Ca}(\mathrm{OH})_{2}$ reduziu-o de 57 para 53\%, a mesma quantidade de Ca, na forma de sulfato, reduziu-o para $43 \%$. Em nosso País, esses estudos tiveram início através de pesquisadores da EMBRAPA. 
Assim, RITCHEY et alii (1981), observaram, em amostras de um Latossolo Vermelho Escuro-argiloso, que o sulfato de cálcio ( $2 \mathrm{t} / \mathrm{ha}$ de $\mathrm{Ca}$ ) movimentou-se em profundidade, com a maior concentração entre 45-60 cm. EMBRAPA (1981) mostra que, num solo LE que havia recebido 4 t/ha de calcário e $0,2,5$ e 5,0 t/ha de gesso, após quatro anos, onde se aplicou apenas calcário, o cálcio e o magnésio havia se movimentado a tē $35 \mathrm{~cm}$ de profundidade, enquanto que nos tratamentos que receberam gesso, atingiram camadas mais profundas do solo, ten do sido encontrados teores próximos de 1,0 meq/100 9 nas camadas de $70-90 \mathrm{~cm}$.

o cultivo de milho nessas áreas mostrou severos sintomas de murcha em grande parte dos tratamentos sem gesso, e situação normal na maioria dos tratamentos com gesso, efeito também anteriormente observado por LOBATO \& RITCHEY (1980) em parcelas que receberam a aplicação de superfos fato simples. Observações em lavouras comerciais, onde ocorreu um verânico de 30 dias, mostraram a importância da correção do subsolo, pois, na propriedade onde o solo havia sido cultivado por cinco anos e onde foram utilizados $984 \mathrm{~kg}$ de gesso (a fonte de fósforo foi o superfosfato simples que contêm aproximadamente $60 \%$ de gesso) a produtividade foi de $2.760 \mathrm{~kg} / \mathrm{ha}$ de. soja, enquanto na lavoura onde cultivou-se o solo por dois anos e, onde usou-se. o superfosfato triplo, a produtividade foi de $1.020 \mathrm{~kg} / \mathrm{ha}$ (SILVA \& RITCHEY, 1982). Atra vés de trincheiras, observou-se que as raízes de soja na 
ārea de 50 ano desenvolveram-se até $1,40 \mathrm{~m}$, enquanto na área de $2 \%$ ano se restringiram aos $0,80 \mathrm{~m}$.

Estudos realizados em outras instituições de pesquisa, como os de LOPES \& ALVES (1981), também demonstra ram que os tratamentos mais eficientes na redução do Al do subsolo foram o superfosfato simples e o gesso. ALVES \& LOPES (1983), estudando combinações de doses duplas de calcário micropulverizado ou dose simples de calcário comercial mais dose simples de calcário micropulverizado com gesso, verifica ram que as mesmas foram altamente eficientes na diminuição da saturação de Al até a camada de $60-80 \mathrm{~cm}$. Outros trabalhos mostrando o efeito da aplicação do gesso no desenvolvimento radicular e na produtividade das culturas podem ser encontrados em SOUZA \& RITCHEY (1986).

Os mecanismos pelos quais o gesso causa a diminuição da acidez subsuperficial são citados em PAVAN \& VOLK WEISS (1986), que resume o conhecimento atual: formação de $\mathrm{AlSO}_{4}^{+}$não tóxico, por reação entre o $\mathrm{Al}^{3+}$ (deslocado do complexo de troca pelo $\mathrm{Ca}^{2+}$ do gesso) com o $\mathrm{SO}_{4}^{2-}$ e formação de compostos Al-hidroxi-sulfato (PAVAN et alii, 1986). Resultam disso, diminuição na saturação em aluminio (valor m) e aumento na participação de Ca na capacidade de troca catiônica (CTC) .

Por outro lado, doses elevadas de gesso, usadas isoladamente, pođem promover a lixiviação de potássio $\left(\mathrm{K}^{+}\right)$ e magnēsio $\left(\mathrm{Mg}^{++}\right)$. Assim, REEVE \& SUMNER (1972), em estudos 
em casa-de-vegetação, mostraram que aplicações elevadas de gesso, acima de $3,0 \mathrm{meq} / 100 \mathrm{~g}$, causaram perdas de mais de meta de de Mg nativo, cerca de $1,7 \mathrm{meq} / 100 \mathrm{~g}$. Já RITCHEY et alii (1981), em ensaios conduzidos em condições de coluna de solo e de campo, mostraram que a aplicação isolada de gesso promoveu uma lixiviação de $\mathrm{K}^{+}$mais intensa do que a observada quan do se aplicou calcário e gesso, fato este explicado pelo aumento da CTC do solo. QUAGGIO et alii (1982) e ROSOLEM \& MACHADO (1984), observaram experimentalmente, que a aplicação de gesso no solo provoca também a lixiviação de magnésio e potás sio para horizontes inferiores, o que, entretanto, é evitado, no todo ou em parte, pelo emprego de calcário que libera mais cargas negativas no solo (RAIJ \& QUAGGIO, 1984; SOUZA \& RITCHEY, 1986).

PAVAN et alii (1984), observaram as principais alterações químicas, no perfil de um Latossolo Roxo distrófico, que tinha acidez suficiente no subsolo para restringir 0 desenvolvimento das raizes, pela aplicação de $\mathrm{CaCO}_{3}$ ou $\mathrm{CaSO}_{4}$. $2 \mathrm{H}_{2} \mathrm{O}$ em quantidades iguais a 0,25 e 1,50 vezes a calagem equi valente para neutralização do $\mathrm{Al}^{3+}$ tóxico. Enquanto o $\mathrm{CaCO}_{3}$ teve efeito somente nos primeiros $20 \mathrm{~cm}$, aumentando o pH, CTC e Ca trocável, e diminuindo Mn e Al trocáveis, os tratamentos com $\mathrm{CaSO}_{4} \cdot{ }^{2} \mathrm{H}_{2} \mathrm{O}$ reduziram os níveis de Al e Mn trocáveis por todos os $100 \mathrm{~cm}$ de profundidade do perfil, aumentaram o $\mathrm{Ca}$ trocável, sendo que o $\mathrm{pH}$ e a CTC não foram afetados. 


\subsection{Ensaios com Calcário e Gesso aplicados SEPARADAMENTE}

QUAGGIO et alii (1982), conduziram, durante três cultivos seguidos, um ensaio com amendoim, cultivar Tatu, em Latossolo Roxo Distrófico, empregando cinco doses de calcário dolomítico $(0 ; 1,5 ; 3,0 ; 4,5$ e 6,0 t/ha) e três de gesso $(0,1,0$ e $2,0 \mathrm{t} / \mathrm{ha})$. O calcârio foi aplicado pouco antes do plantio, e o gesso foi distribuído em cobertura no iní. cio do florescimento. Os resultados médios, produção de três safras, indicaram que a maior produção foi obtida quando se usaram as maiores doses de calcário e de gesso. Por outro lado, observou-se diminuição acentuada nos teores de $\mathrm{K}$ e Mg na presença do gesso e ausência de calagem, ou com as doses menores de calcārio.

Uma das conclusões do trabalho é a seguinte: a aplicação do gesso, com o propósito de melhorar as condições de acidez em subsuperficie, deve ser feita sempre associada com doses elevadas de calcário para prevenir o desequilíbrio de bases na camada arávei.

TANAKA et alii (1983), em ensaio instalado em um Latossolo Vermelho Amarelo de patrocínio, MG, com arroz IAC-47 e IAC-25, estudaram a influência da aplicação de doses de calcário dolomitico $(2,7$ e 5,4 t/ha $)$ de gesso nas mesmas doses, aplicados a lanço antes do plantio. Os resultados obti dos revelaram efeitos significativos dos niveis de gessagem e 
de calagem. Interação significativa foi detectada entre gessagem e cultivar, sendo que somente o cultivar IAC-47 respondeu de forma quadrātica, aos níveis de gesso, enquanto que no cultivar IAC-25 não houve influência deste insumo. provavelmente, o efeito benéfico do gesso foi devido ao suprimento de enxofre e de cálcio, haja visto que o solo apresentava baixos teores desses nutrientes, e a saturação de alumínio era considerada baixa.

o gesso e outros materiais foram aplicados em três doses $(0 ; 0,5$ e $1,0 \mathrm{~kg} /$ cova) na cova de plantio de cafeeiros em um LVA, fase cerrado, de patrocínio-MG, após a aplicação de 4 t/ha de calcário dolomítico em área total. os resultados obtidos por FREIRE et alii (1984), no ensaio em que se aplicou gesso e calcário na cova de plantio do cafeeiro, indicaram efeito depressivo do calcārio quando usado isoladamente; resposta quadrática às doses de gesso fornecidas e que a substituição de metade do gesso por calcārio deu praticamen te os mesmos resultados que o gesso isolado, segerindo esses dados que a acidez não era fator limitante e que o gesso funcionou como fonte de $S$, visto que na adubação NPK da cova não foram usados adubos contendo esse elemento.

GUIMARÃES et alii (1983), visando verificar os efeitos corretivos do gesso e do calcário nas camadas subsuperficiais do solo e o valor fertilizante do gesso como forne cedor de s e Ca para o cafeeiro, instalaram um ensaio num La tossolo Roxo Diströfico de são Sebastião do Paraíso-MG. o cal 
cário $(0,750,1500$ e $3000 \mathrm{~kg} / \mathrm{ha})$ e o gesso $(0,1290$ e 2580 $\mathrm{kg} / \mathrm{ha}$ ) foram aplicados à lanço antes do plantio do café. os resultados do primeiro biênio de produção mostraram que na necessidade normal de calagem ( $1500 \mathrm{~kg} / \mathrm{ha}$ ), onde os teores de Ca já foram fornecidos em grande parte pelo calcário, a produ ção de café passou de 29,81 (sem gesso), para 41,50 sacas (2.580 kg/ha de gesso), ou seja, 11,24 sacas a mais de café beneficiado.

PONTES et alii (s/d, a) usaram três doses de calcário e três de gesso em arroz de sequeiro, em Latossolo Vermelho Escuro textura franco-argilo arenosa, fase cerrado. A dose 2 de calcário foi de $3,3 t /$ ha e a dose 1 , metade. A do se 2 do gesso foi de $5,7 \mathrm{t} / \mathrm{ha}$ o que corresponde a $3,3 \times 1,7$; foi adotado o critério de fornecer nos dois corretivos a mesma quantidade de Ca. Antes da aração, foi aplicada metade da dose dos corretivos; o restante foi distribuido antes da gradagem. Os resultados mostraram que houve resposta linear ao calcário, enquanto que o efeito do gesso não foi significativo, embora houvesse tendência para resposta em função das doses aplicadas. Um ensaio semelhante com trigo foi instalado por FONTE et alii (s/d, b), na Estação Experimental da EPAMIG, em Patrocínio, MG, com a variedade NH-1146 consirada pou co sensível ao alumínio.

os dados obtidos mostraram que, em ausência de calagem o gesso conseguiu triplicar a produção de trigo; houve um efeito Iinear do gesso quando associado à dose interme- 
diária de calcário. Um terceiro ensaio, semelhante aos anteriores, foi conduzido por PONTE et alii (s/d, c), com os culti vares de soja UF-VI e IAC-2, em Latossolo Vermelho - Amarelo da Estação Experimental da EPAMIG, em Patrocívio, MG, sendo que posteriormente santos et alii (s/d, d), citados em MALAVOLTA et alii (1986), utilizaram as mesmas variedades de soja no mesmo local do experimento anterior. o gesso e o calcário foram usados nas mesmas doses $(0 ; 2,7$ e 5,4 t/ha), combinadas de todos os modos possiveis num esquema fatorial. os resultados obtidos, em ambos os ensaios, mostraram que os aumentos médios nas colheitas devido ao calcārio foram, pratica mente, os mesmos obtidos com o gésso, sugerindo que o efeito maior deve ser causado por Ca contido nos corretivos, embora não se possa descartar outros efeitos.

\subsection{Ensaios com Calcario e Gesso Aplicados Conjuntamente}

Outra alternativa bastante promissora è a uti lização simultânea de calcārio e gesso em proporções equilibradas. Uma das vantagens dessa opção é que a quantidade da mistura a ser utilizada pode ser determinada facilmente pelo critério da elevação da saturação em bases, através do PRNT da mistura, alëm de permitir a aplicação dos dois produtos numa ūnica operação (VITTI \& FERREIRA, 1986). 
Assim, ALVES \& LOPES (1983), estudando combina ções de doses duplas de calcārio micropulverizado, pelo crité rio de calagem utilizado em Minas Gerais e Goiás, ou dose sim ples de calcário comercial mais doses simples de calcário micropulverizado com gesso, observaram que os mesmos foram alta mente eficientes na diminuição da saturação de Al (m), até a camada de $60-80 \mathrm{~cm}$ de profundidade.

Em ensaios conduzidos por DEMATTE (1986), num Latossolo Textura média arenosa, álico, de ocorrência em Pirassununga-SP, empregando-se mistura de calcário calcinado com gesso (66:34), verificou-se que a mesma foi eficiente para aumentar o teor de $\mathrm{Ca}, \mathrm{Mg}$ e $\mathrm{S}_{-} \mathrm{SO}_{4}^{2-}$ na superficie e em profundìdade, o mesmo acontecendo com a saturação em bases (Vo); houve diminuição no teor de Al trocável e na participação des te na CTC efetiva; houve enriquecimento de $K$ e Mg nas camadas mais profundas, permanecendo os elementos na zona usualmente ocupada pelas raízes de cana (cultura subsequente). Além do mais, um solo álico tornou-se não ālico. 


\section{MATERIAL E MÉTODOS}

\subsection{Local de Condugão dos Ensaios}

Os ensaios em vasos com terra foram conduzidos em casa-de-vegetação do Departamento de Química da Escola Superior de Agricultura "Luiz de Queiroz", Piracicaba-sP, no período de fevereiro a maio de 1983.

Os ensaios em condições de campo foram conduzi dos nos municípios de Capão Bonito, Sorocaba e Itapeva, Estado de são paulo, no ano agrícola $1983 / 84$.

\subsection{ENSAios em CASA-DE-VEgETASÃO}

\subsubsection{Delineamento Estatístico}

Experimento inteiramente casualizado, com 5 tratamentos e 4 repetições, considerando-se como unidade expe rimental um vaso, com 3 Iitros de terra, contendo 3 plantas. 


\subsubsection{Solos}

Os solos utilizados pertencem às unidades de meapeamento Podzólico Vermelho Amarèlo (PVA) e Latossolo Vermelho Escuro textura média (LEm), dos municípios de Capão Bonito e Sorocaba, respectivamente, Estado de são Paulo.

\subsubsection{Cultivar Utilizado}

o vegetal empregado como planta teste foi o mi Iho (Zea mays L.), cultivar Piranão (VD-2). As sementes foram obtidas no Departamento de Genética da E.S.A. "Luiz de Queiroz" :

\subsubsection{Recipientes}

Foram utilizados vasos de argila com capaciąa de para 3 litros de TFSA, pintados internamente com Neutrol, dotados de coletores e apresentando no fundo dos mesmos um $\mathrm{f} \underline{\mathrm{u}}$ ro central de $1 \mathrm{~cm}$ de diâmetro para facilitar a aeração. Empregou-se uma tela fina de nylon para evitar a passagem de ter ra.

\subsubsection{Material Corretivo}

Os materials corretivos utilizados constaram de calcário dolomítico calcinado, gesso agrícola e as mistu 
ras de ambos em duas proporções, cujas caracteristicas quími cas são apresentados na Tabela 1. Quanto às características físicas, todos os produtos passaram na peneira 50 (ABNT) de $0,3 \mathrm{~mm}$.

Tabela 1. Principais características químicas dos produtos.

\begin{tabular}{lcccc} 
Produto & CaO & Mgo & S & P.N. \\
\hline Calcário calcinado & 46 & 22 & - & 136 \\
$\begin{array}{l}\text { Gesso } \\
\text { Calcário calcinado } \\
+ \text { Gesso }(90: 10)\end{array}$ & 28 & - & 17 & - \\
$\begin{array}{l}\text { Calcário calcinado } \\
+ \text { Gesso }(70: 30)\end{array}$ & 44 & 20 & 1,7 & 123 \\
& 40 & 15 & 5,0 & 95 \\
\hline
\end{tabular}

\subsubsection{Metodologia Seguida}

3.2.6.1. Coleta e preparo dos solos

Os solos foram coletados dos locais já citados em 3.2.2., na profundidade de $0-20 \mathrm{~cm}$, os quais foram des torroados e postos a secar à sombra, passados em peneira com malha de $2 \mathrm{~mm}$ e uniformizados por misturas sucessivas de porções. Em seguira foram tiradas amostras para anālise labora- 
torial As principais características quimicas desses solos encontram-se na Tabela 2 .

\section{$3.2 \cdot 6.2$. Incubação dos solos}

Com base nas anālises químicas de cada solo, foram determinadas as necessidades de calagem para elevar o pH a 6,5, seguindo o proposto por CATANI \& GALLO (1955), para os tratamentos com calcário dolomítico calcinado e/ou misturas calcário + gesso. Calculou-se uma dose para suprir as mesmas quantidades de CaO aplicadas como calcārio dolomítico calcinado, quando o gesso foi usado separadamente. Assim, as quantidades de produtos empregadas foram as discriminadas na Tabela 3 .

Numa bandeja plástica, foi colocado, de cada vez, 3 litros de terra e a quantidade de material corretivo, de acordo com os tratamentos, que, depois de bem homogenizados, foram colocados nos respectivos vasos. Em seguida, adicionou-se água destilada para manter os solos com $70 \%$ do poder āe embebição; cobriu-se com um plästico e deixou-se os so Ios assim incubados por um periodo de 20 dias.

\subsubsection{Adubação băsica}

Apōs o período de incubação, procedeu-se à adu bação bāsica da terra dos vasos, baseada em MALAVOL'TA (1980), conforme discriminado na Tabela 4. 


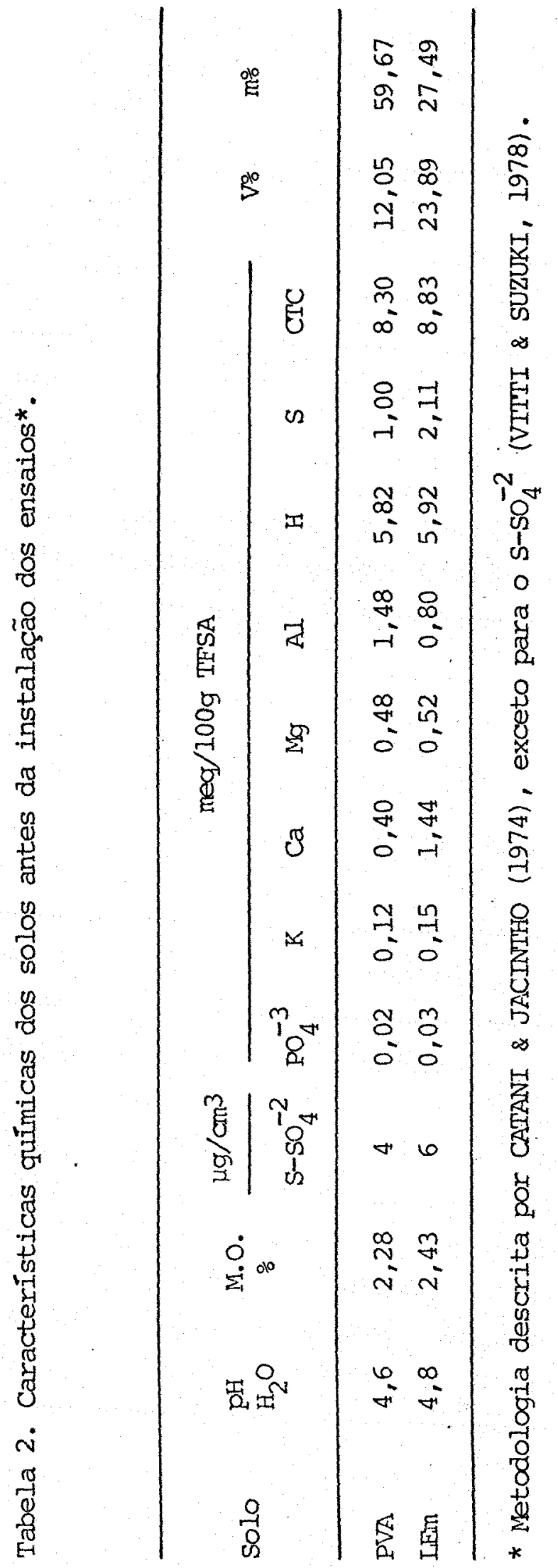


Tabela 3. Produtos e quantidades utilizados em função dos trą tamentos.

Tratamento

Solo

\begin{tabular}{lcc}
\cline { 2 - 2 } & PVA & LEm \\
\hline 1. Testemunha & 0 & 0 \\
2. Calcário calcinado & 4,89 & 4,20 \\
3. Gesso & 8,04 & 6,89 \\
4. Calcário calcinado + gesso $(90: 10)$ & 5,13 & 4,41 \\
5. Calcário calcinado + gesso $(70: 30)$ & 5,82 & 5,01 \\
\hline
\end{tabular}

Tabela 4. Adubação básica e época de aplicação.

\begin{tabular}{lccc}
\hline Nutrientes & ppm & Fonte & Epoca de aplicação \\
\hline Nitrogênio (N) & 150 & uréia & $\begin{array}{r}50 \mathrm{ppm} \text { no plantio } \\
100 \mathrm{ppm} \text { em cobertura }\end{array}$ \\
Fósforo (P) & 200 & $\mathrm{SPT}$ & no plantio \\
Potássio (K) & 150 & $\mathrm{KCl}$ & $50 \mathrm{ppm}$ no plantio \\
& & & $100 \mathrm{ppm}$ em cobertura \\
Boro (B) & 0,5 & $\mathrm{H}_{3} \mathrm{BO}_{4}$ & no plantio \\
Molibdênio (Mo) & 0,1 & $\mathrm{Na}_{2} \mathrm{MOO}_{4} \cdot 2 \mathrm{H}_{2} \mathrm{O}$ no plantio \\
Zinco (Zn) & 2,5 & $\mathrm{ZnSO}_{4} \cdot 7 \mathrm{H}_{2} \mathrm{O}$ no plantio \\
\hline
\end{tabular}


Foram preparadas soluções e/ou suspensões de N, P e K, separadamente, e uma solução ūnica de B, Mo e Zn, a saber:

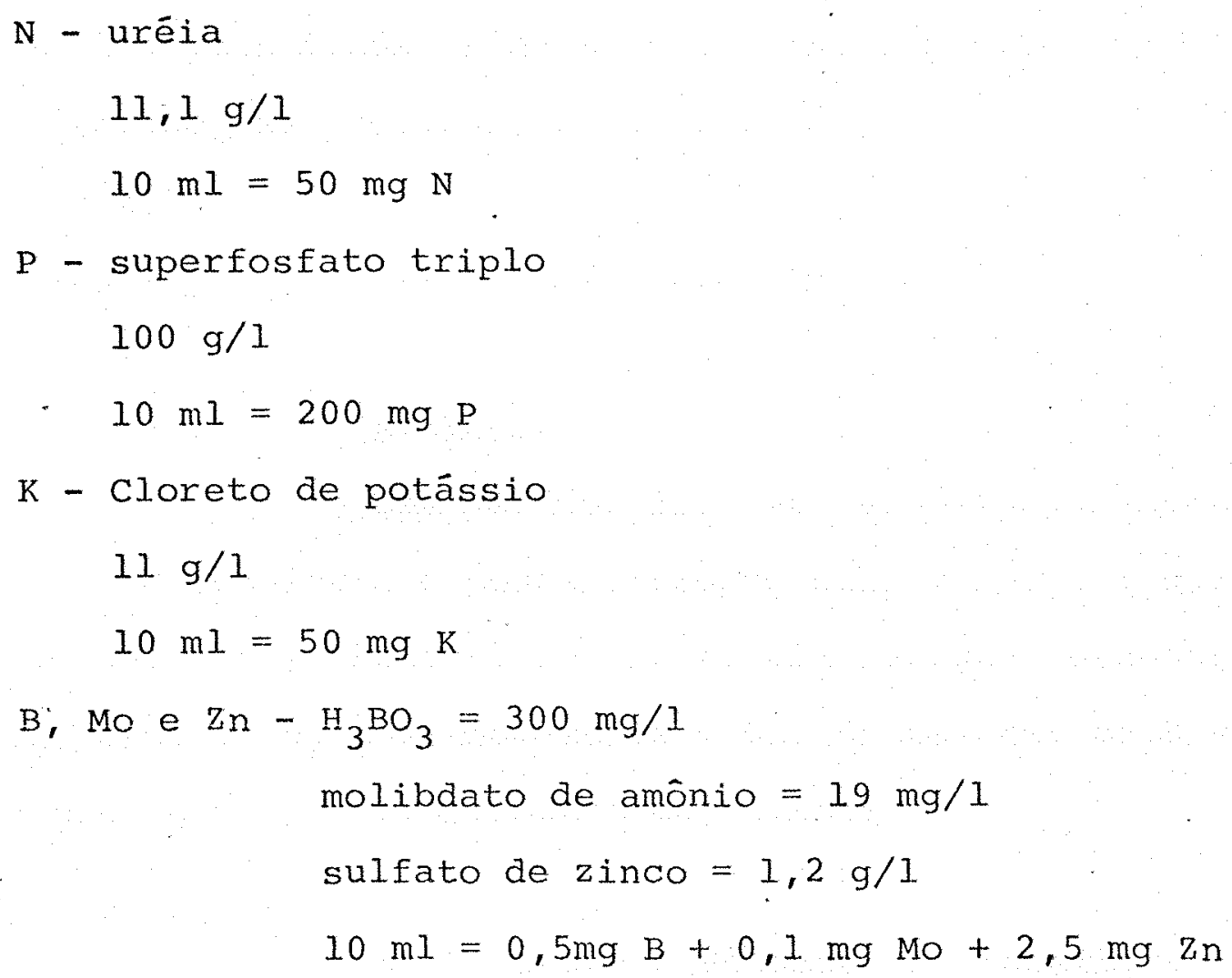

A terra de cada vaso foi colocada numa bandeja plästica, adicionando-se as soluções e/ou suspensões, uma de cada vez, que, depois de muito bem homogeneizada, foram devolvidas aos vasos. Em seguida, completou-se com āgua destilada de modo de tex-se $70 \%$ do poder de embebição. Cobriu-se com um plästico por um período de 8 dias

\subsubsection{Semeadura}

Uma semana após a adubação, procedeu-se à se- 
meadura. Antes porēm, as sementes foram desinfectadas, mergu lhando-as numa solução de água sanitāiria (Q Boa) diluída ( 1 + 10) por 5 minutos, sendo, em seguida, lavadas com 3 porções de água destilada. Finalmente, foram distribuídas 8 sementes por vaso, na profundidade de $2,0 \mathrm{~cm}$.

3.2.6.5. Condução dos ensaios

a) Regas

Uma vez por dia, até aproximadamente 20 dias após a semeadura e posteriormente duas vezes por dia, até a colheita dos ensaios, foi restituída a água evapotranspirada, de cada vaso, baseando-se na mëdia de pesagem de 8 vasos ao acaso e no desenvolvimento das plantas.

b) Desbaste e adubação em cobertura

Aos oito dias após a germinação, procedeu - se ao desbaste, deixando-se 3 plantas por vaso.

Aos 21 dias após a germinação, foi feitá a adu bação em cobertura, na base de 100 ppm de $\mathrm{N}$ e K, com uma solú ção contendo uréia e cloreto de potássio.

c) Colheita dos ensaios

Aos 45 dias após a germinação, procedeu-se à colheita da parte aérea das plantas, cortando-as rente ao so 10. Em seguida, foram secas em estufa (709C) até peso cons- 
tante. Posteriormente, pesou-se a parte aérea das plantas de cada vaso e moeu-se para se fazer a anālise mineral. Uma sema na após a colheita da parte aérea, procedeu-se à coleta das raizes e de amostras de terra de cada vaso. Em seguida, as raízes foram lavadas com água destilada, postas a secar em es tufa até peso constante e posteriormente pesadas.

d) Anälises minerais

$\mathrm{Na}$ parte aérea das plantas foram determinados os teores de N, P, K, Ca, Mg, S, Mn e Al, no Laboratório do Departamento de Química da ESALQ.

Nos solos, foram realizadas as análises de rotina, no Departamento de Solos, Geologia e Fextilizantes da ESALQ e o $\mathrm{S}^{-\mathrm{SO}_{4}^{2-}}$ foi determinado no Laboratório de Fertilidade de Solo da Indústria Mineradora Pagíiato Ltaa.

\subsection{Ensaios de Campo}

\subsubsection{Delineamento Estatístico}

Blocos ao acaso, com 5 tratamentos e 4 repeti Ções, considerando-se como unidade experimental uma parcela de $25 \mathrm{~m}^{2}$, para a cultura de milho e para a sucessão soja / tri go $22,5 \mathrm{~m}^{2}$. 


\subsubsection{Solos}

Os solos utilizados para a cultura de milho fo ram os mesmos já citados para os ensaios em casa-de-vegetação. Para a sucessão soja/trigo, utilizou-se um Latossolo Roxo (LR), de ocorrência no município de Itapeva-SP.

\subsubsection{Amostragem dos Solos e Análise Química}

Antes da instalação dos ensaios, foi feita a amostragem dos solos a duas profundidades: $0-20$ e $21-40$ cm, separadamente. Foi tirada uma amostra composta, formada de 20 subamostras, para superficie e profundidade, respectiva mente.

As anālises de rotina foram realizadas no Departamento de Solos, Geologia e Fertilizantes da ESALQ. As determinações de $\mathrm{S}^{-\mathrm{SO}_{4}^{2}}{ }_{4}^{-}$foram feitas no Laboratório de Fertilidade de Solo da Indústria Mineradora Pagliato Ltda. As caracteristicas quimicas desses solos encontram-se na Tabela 5.

\subsubsection{Tratamentos}

Os tratamentos foram os mesmos empregados em casa-de-vegetação. o calcário calcinado e as misturas calcário calcinado + gesso, foram aplicados para elevar a satura- 
Tabela 5. Características químicas dos solos antes da instalação dos ensaios *

\begin{tabular}{|c|c|c|c|c|c|c|c|c|c|c|c|c|c|c|}
\hline \multirow{2}{*}{ Solo } & \multirow{2}{*}{$\begin{array}{l}\text { Prof. } \\
\text { cm }\end{array}$} & \multirow{2}{*}{$\begin{array}{l}\mathrm{pH} \\
\mathrm{H}_{2} \mathrm{O}\end{array}$} & \multirow{2}{*}{$\begin{array}{l}\text { M.O. } \\
\frac{\circ}{\partial}\end{array}$} & \multirow{2}{*}{$\frac{\mu \mathrm{g} / \mathrm{cm}^{3}}{\mathrm{~s}^{-\mathrm{sO}_{4}^{-2}}}$} & \multicolumn{8}{|c|}{ meq $/ 100 \mathrm{~cm}^{3}$ TFSA } & \multirow{2}{*}{ Vo } & \multirow{2}{*}{$\mathrm{m} \%$} \\
\hline & & & & & $\mathrm{PO}_{4}^{-3}$ & $\mathrm{~K}$ & $\mathrm{Ca}$ & $\mathrm{Mg}$ & $\mathrm{H}+\mathrm{Al}$ & Al & $\mathrm{S}$ & CTC & & \\
\hline \multirow[t]{2}{*}{ PVA } & $0-20$ & 4,8 & 2,27 & 4 & 0,02 & 0,12 & 1,64 & 0,65 & 7,34 & 0,85 & 2,41 & 9,75 & 24,71 & 26,07 \\
\hline & $21-40$ & 4,6 & 1,86 & 7 & 0,01 & 0,08 & 1,25 & 0,28 & 8,62 & 1,20 & 1,61 & 10,23 & 15,73 & 42,70 \\
\hline \multirow[t]{2}{*}{ LEm } & $0-20$ & 5,0 & 3,19 & 6 & 0,03 & 0,15 & 2,40 & 0,88 & 6,89 & 0,58 & 3,43 & 10,32 & 33,23 & 14,46 \\
\hline & $21-40$ & 4,6 & $2,45^{\circ}$ & 9 & 0,01 & 0,09 & 1,12 & 0,31 & 7,64 & 1,42 & 1,52 & 9,16 & 16,59 & 48,29 \\
\hline \multirow[t]{2}{*}{$I R$} & $0-20$ & 4,9 & 3,20 & 1 & 0,05 & 0,14 & 1,30 & 0,85 & 6,50 & 0,60 & 2,29 & 8,79 & 26,05 & 20,76 \\
\hline & $21-40$ & 4,7 & 2,40 & 2 & 0,02 & 0,10 & 0,75 & 0,60 & 6,40 & 0,90 & 1,45 & 7,85 & 18,47 & 38,29 \\
\hline
\end{tabular}

* Metodologia descrita em CATANI \& JACINTHO (1974), excessão feita ao S-SO ${ }_{4}^{2-}$ (VIITI \& SUZUKI, 1973). 
ção em bases a 70\%, conforme RAIJ et alii (1985). As doses de gesso foram estimadas para suprir as mesmas quantidades de CaO aplicadas como calcário calcinado, quando este foi usado separadamente.

o resumo dos tratamentos e quantidades de produtos utilizados encontram-se na Tabela 6, enquanto que as características do produto são as mesmas descritas na Tabela 3.

Tabela 6. Produtos e quantidades utilizados em função dos tra tamentos.

t/ha

Tratamentos

$\overline{\text { PVA }} \quad$ LEm LR

1. Testemunha

0

2. Calcário calcinado

3. Gesso

4. Calcário calcinado + gesso (90:10)

5. Calcārio calcinado + gesso $(70: 30)$
3,24

5,33

3,59

4,65
0

0

2,79

2,84

4,58

4,67

3,09

3,14

3,99

4,07

3.3.5. Culturas Utilizadas

Os vegetais escolhidos como plantas testes fo- 
ram os seguintes: milho hibrido (Zea mays L.) Agroceres; Soja (Glycine max L. Merrill) Bossier e trigo (Triticum aestivum L.) IAC-17.

\subsubsection{Instalação dos Ensaios}

Após o preparo do solo, que constou inicialmen te de uma roçada da vegetação nativia, aração e gradagem, pro cedeu-se à demarcação das parcelas e em seguida a incorporação dos materiais corretivos, na profundidade de $25 \mathrm{~cm}$, com auxilio de enxada rotativa, acoplada a microtrator Agrale.

As áreas assim preparadas ficaram em repouso por um período de 20 dias.

\subsubsection{Semeadura e Adubação}

A semeadura e adubação de plantio foram feitas simultaneamente, com plantadeira-adubadeira Lavrale, de 2 linhas, acoplada a microtrator.

Para a cultura do milho, todos os tratamentos receberam uma adubação bāsica NPK + micronutriente, enquanto que para soja aplicou-se apenas PK + micronutriente. As dosagens encontram-se discriminadas na Tabela 7 .

Para a cultura de milho, o espaçamento foi de 1,0 m entre linhas e 9 a 10 sementes por metro de sulco, cons tando cada parcela de 5 linhas de $5,0 \mathrm{~m}$. 
Tabela 7.. Adubação básica aplicada nos ensaios de campo para as culturas de milho e soja.

$\mathrm{kg} / \mathrm{ha}$

Nutrienties

Fonte Plantio Cobertura

\begin{tabular}{lcrc} 
Nitrogênio $(\mathrm{N})$ & urēia & 20 & 40 \\
Fósforo $\left(\mathrm{P}_{2} \mathrm{O}_{5}\right)$ & $\mathrm{SPT}$ & 180 & - \\
Potássio $\left(\mathrm{K}_{2} \mathrm{O}\right)$ & $\mathrm{KCl}$ & 30 & 30 \\
Zinco $(\mathrm{Zn})$ & $\mathrm{ZnSO}_{4} \cdot 7 \mathrm{H}_{2} \mathrm{O}$ & 5 & - \\
\hline
\end{tabular}

No caso da cultura de soja, o espaçamento foi de 0,5 m entre linhas com 25 a 30 sementes por metro de sulco, ficando cada parcela com 9 linhas de $5,0 \mathrm{~m}$.

As sementes de soja foram antes inoculadas com Rhizobium japonicum.

\subsubsection{Condução dos Ensaios}

3.3.8.1. Desbaste e adubação em cobertura

Os ensaios com milho e/ou soja foram desbasta dos aos. Il dias após a germinação, deixando-se 5 e 17 plantas, respectivamente, por metro de sulco.

Aos 35 dias após a germinação, procedeu-se à adubação em cobextura. 
Para o ensaio com milho, aplicou-se $40 \mathrm{~kg} / \mathrm{ha}$ de $\mathrm{N}$ (uréia) e $30 \mathrm{~kg} / \mathrm{ha}$ de $\mathrm{K}_{2} \mathrm{O}(\mathrm{KCl})$, enquanto que para 0 ensaio com soja aplicou-se apenas $30 \mathrm{~kg} / \mathrm{ha}$ de $\mathrm{K}_{2} \mathrm{O}$ (KCl).

\subsubsection{Tratos culturais}

Foram realizados todos os tratos culturais de rotina, como capinas e controle fitossanitários.

o ensaio com soja recebeu, ainda, irrigação por aspersão em períodos de maior necessidade da cultura.

\subsubsection{Cultivo do Trigo em Sucessão à Soja}

Logo após a colheita da soja (abril/84), proce deu-se o plantio de trigo no mesmo sulco anterior, utilizando se apenas da adubação residual da leguminosa.

Aos 35 dias da germinação, aplicou-se $20 \mathrm{~kg} / \mathrm{ha}$ de $\mathrm{N}$ (uréia), e $30 \mathrm{~kg} / \mathrm{ha}$ de $\mathrm{K}_{2} \mathrm{O}$ (KCl). Foram executados todos os tratos culturais já descrițos para as culturas anterio res. A cultura recebeu irrigação por aspersão nos seus perío dos mais críticos.

\subsubsection{Colheita dos Ensaios}

Em todos os ensaios, foi colhida manualmente a área total de cada parcela. o milho e a soja foxam debulha dos com auxilio de uma batedeira de cereais, marca LAREDo aco 
plada a trator. o trigo foi debulhado manualmente. Determi nou-se a umidade dos grãos e fez-se a correção para 13\%. Em seguida, pesou-se a produção de grãos de cada parcela. Finalmente, fez-se amostragem do solo em cada parcela, a duas profundidades $(0-20$ e $21-40 \mathrm{~cm})$, nas linhas (L) e entrelinhas (EL) de plantas, para análise química. No caso de sucessão soja/trigo, foram feitas amostragens após a colheita da soja e após a colheita do trigo. 


\section{RESULTADOS E DISCUSSAO}

\subsection{Ensaios em Casa-de-Vegetacão}

Na Tabela 8 são apresentadas as médias gerais de produção de matéría seca total (parte aérea + raízes) de milho, bem como, o resumo da anälise de variância.

Analisando-se os dados dessa tabela, observase o efeito significativo dos tratamentos, obedecendo a seguinte ordem decrescente:
a) Solo PVA - Capão Bonito
Calcário calcinado + gesso $(70 \% 30 \%)>$ Calcário calcinado + Gesso $(90 \%: 10 \%)=$ Calcário calcinado $\geqslant$ Gesso $=$ Testemunha.

b) Solo LEm - Sorocaba

Calcārio calcinado + gesso $(70 \%: 30 \%)>$ Calcário calcinado + gesso $(90 \%: 10 \%)>$ Calcário calcinado = Gesso > Testemuntia.

Observa-se, portanto, o efeito positivo e significativo do uso de corretivos na produção de matéria seca, sendo esse efeito superior no tratamento que recebeu a apli- 


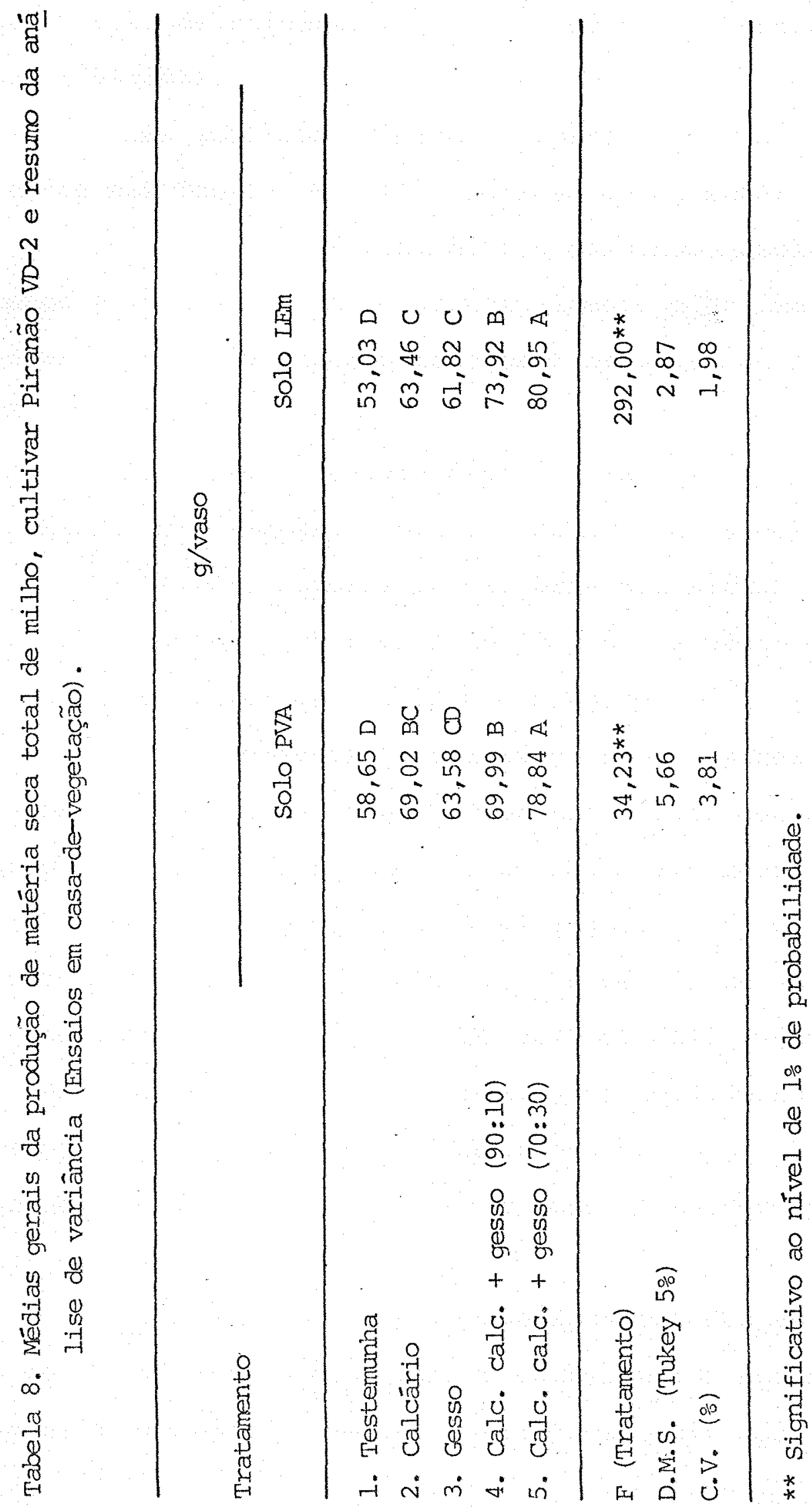


cação da mistura de calcário dolomítico calcinado + gesso na proporção $(70 \%: 30 \%)$.

As anālises químicas da parte aérea do milho encontram-se nas Tabelas 9 e 10. Nota-se o seguinte:

1) o calcārio dolomitico calcinado isoladamente aumentou o teor de cálcio e principalmente o de magnésio na parte aérea do milho, diminuindo os teores de manganês e alumínio;

2) O gesso separadamente aumentou os teores de cálcio, enxôfre e manganês, diminuindo o teor de aluminio;

3) As misturas de calcário dolomitico calcinado + gesso aumentaram os teores de cálcio, magnésio e enxofxe, baixando os teores de alumínio e manganês.

Provavelmente, a diferença não significativa entre os tratamentos calcário dolomítico calcinado e gesso, quando aplicados separadamente, se devem aos seguintes mo tivos: (1) não houve condições de lixiviação, logo, o efeito negativo do gesso na Iixiviação de $\mathrm{K}$ e Mg deixou de manifestar-se, conforme já observado por QUAGGIO et alii (1982) e ROSOLEM \& MACHADO (1984); (2) o ensaio foi colhido num perío do de tempo relativamente curto, não chegando a ser limitante o teor de magnésio do solo; (3) o gesso forneceu cálcio e enxorxe para as plantas.

Nas Tabelas 11 e 12 são apresentadas as anālises dos dois solos estudados, após a colheita dos ensaios. ob serva-se as mudanças em suas caracteristicas químicas, a saber: 


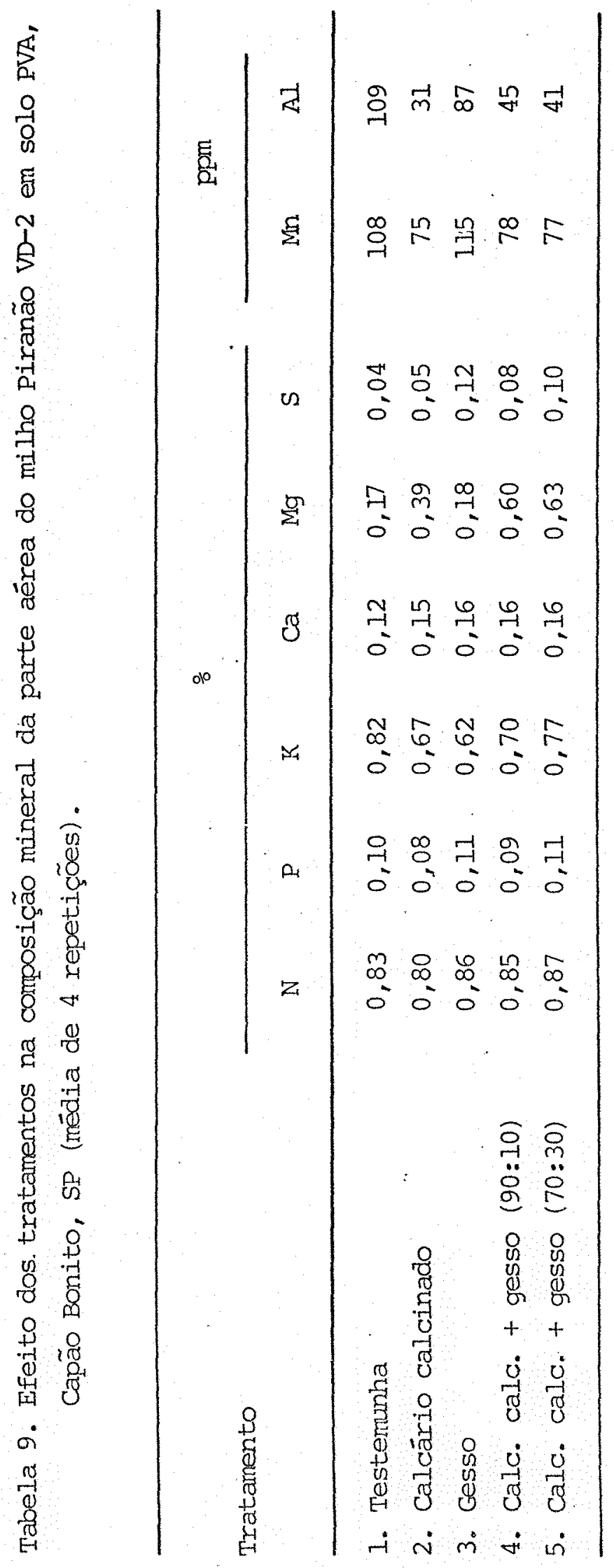




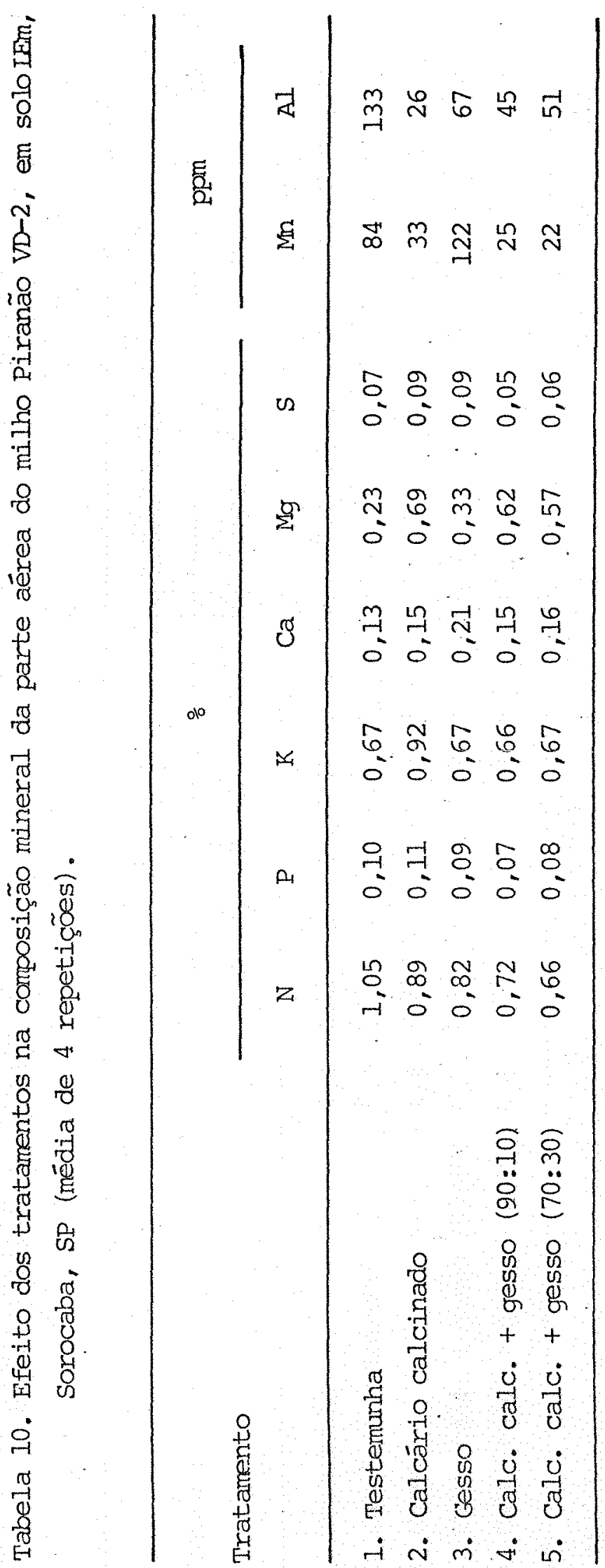




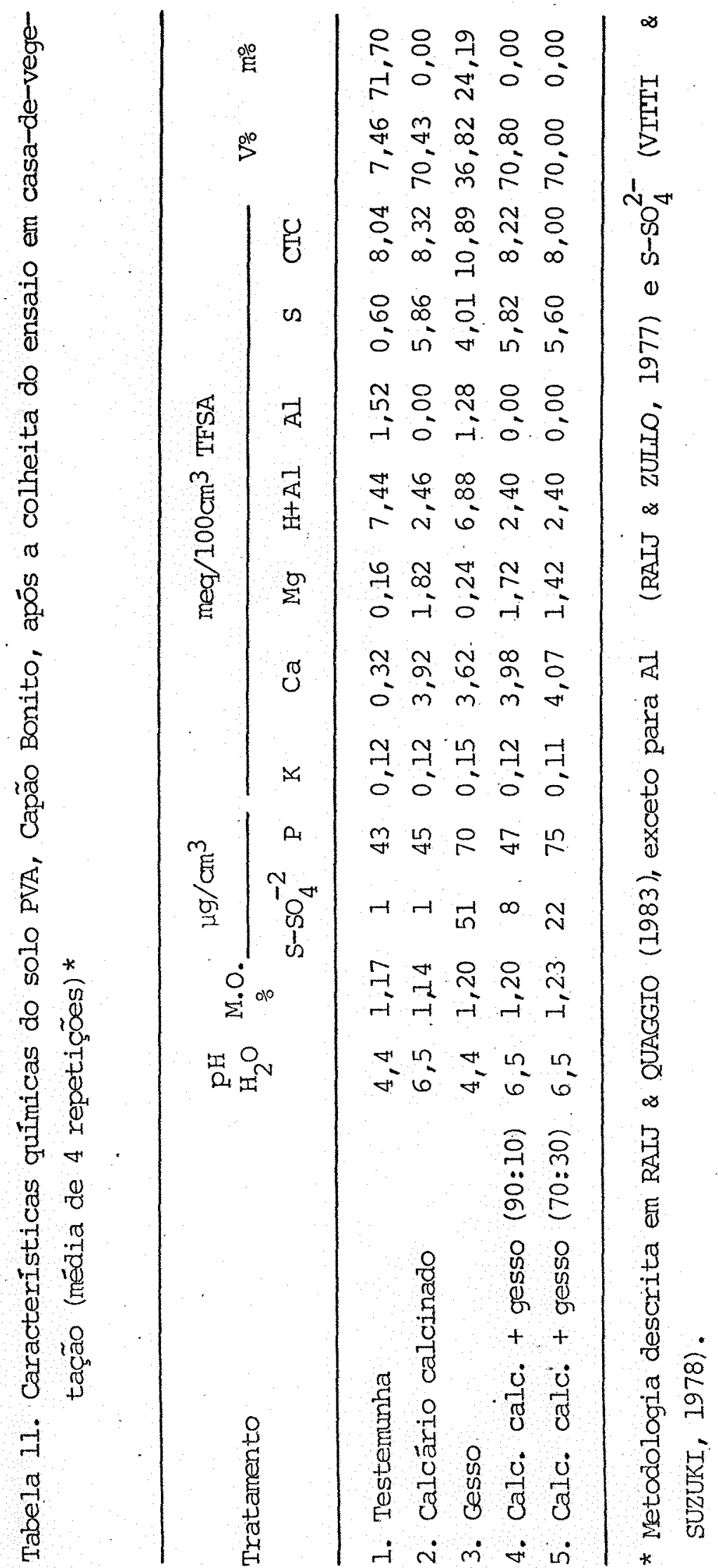




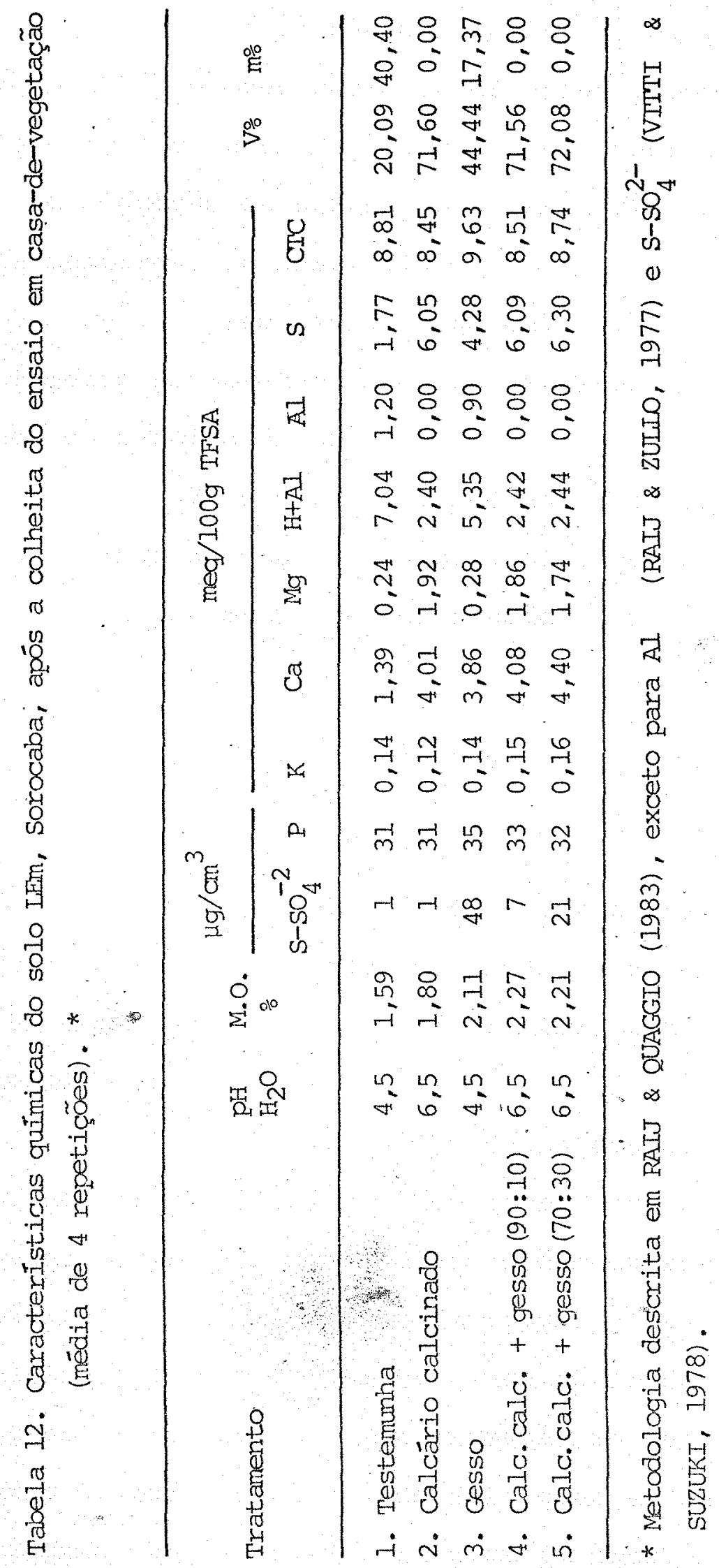


1) o calcário dolomítico calcinado aplicado isoladamente promoveu correção da acidez, com elevação do pH; neutralização do alumínio, aumento nos teores de cálcio e mag nésio; diminuição da acidez potencial $\left(\mathrm{H}^{\circ}+\mathrm{Al}+3\right)$ e elevação da saturação em bases (V\%);

2) as misturas de calcário dolomítico calcinado + gesso promoveram, alêm dos efeitos anteriores, aumento no teor de enxofre $\left(\mathrm{S}^{-\mathrm{SO}_{4}^{2-}}\right)^{2-}$;

3) o gesso, quando usado separadamente, propor cionou aumento no teor de cálcio, elevação da saturação em bạ ses e redução na saturação de alumínio (m) .

\subsection{ENSAIOS DE CAMPO}

Nas Tabelas 13 e 14 estão apresentados, respectivamente, os resultados de produção de grãos de milho (so los PVA e LEm), soja e trigo (solo LR), bem como o resultado das análises de variância.

Analisando-se os dados dessas tabelas, observarse, nos três solos estudados, o efeito significativo dos tratamentos, seguindo a seguinte ordem decrescente: calcário dolomîtico calcinado + gesso $(70 \%: 30 \%)>$ calcârio dolomítico calcinado + gesso $(90 \%: 10 \%)>$ calcârio dolomítico calcina do > gesso > testemunha, com excessão do solo LEm, em que o calcário dolomítico calcinado foì igual ao calcârio dolomítico calcinado + gesso $(90 \%: 10 \%)$ e o gesso foi igual à testemunha. 
Nota-se o seguinte:

1) a mistura calcário dolomítico calcinado ... + gesso (70\%:30\%) apresentou um efeito superior a todos os outros tratamentos;

2) a mistura calcário dolomítico calcinado + gesso (90\%:10\%) e calcário dolomítico calcinado isoladamente tiveram efeitos intermediários;

3) o menor efeito foi observado para a testemunha e, em seguida, para o gesso quando aplicado separadamen te.

Os resultados das anālises dos solos, realizadas após a colheita dos ensaios, encontram-se nas Tabelas 15 a 18.

Nota-se as alterações em suas características quimicas, a saber:

1) o calcário dolomítico calcinado e as misturas de calcário dolomítico calcinado + gesso tiveram comportamento semelhante na camada de $0-20 \mathrm{~cm}$ de profundidade: corrigindo os solos, com elevação do $\mathrm{pH}$; aumentando os teores de cálcio e magnésio; diminuindo a acidez potencial $\left(\mathrm{H}^{\circ}+\mathrm{Al}^{+3}\right)$; aumentando a saturação em bases (Vo) e neutralizando o aluminio;

2) em profundidade $(21-40 \mathrm{~cm})$, os mesmos trata mentos apresentaram efeitos menores, sendo que a mistura de calcário dolomítico calcinado + gesso (70\%:30\%) se mostrou superior ao calcário dolomítico calcinado e à mistura calcárjo dolomitico calcinado + gesso $(90 \%: 10 \%)$; 
3) as misturas de calcārio dolomitico calcinado + gesso aumentaram o teor de $\mathrm{S}_{-} \mathrm{SO}_{4}^{-2}$ dos solos, sendo esse aumento mais acentuado em profundidade $(21-40 \mathrm{~cm})$;

4) o gesso quando aplicado em separado praticamente não modificou $\circ \mathrm{pH}$ dos solos, aumentando, no entanto, os teores de $\mathrm{S} \mathrm{SO}_{4}^{-2}$, cálcio, a saturação em bases (V\%) e reduzindo a saturação de alumínio $(\mathrm{m})$, sendo esses efeitos mais acentuados em profundidade $(21-40 \mathrm{~cm})$;

5) no tratamento somente com gesso, houve uma maior lixiviação de $\mathrm{K}^{+}$e $\mathrm{Mg}^{+2}$. Resultados semelhantes foram. também obtidos por REEVE \& SUMMER (1972), PAVAN et alii (1984) e DEMATTE (1986). 


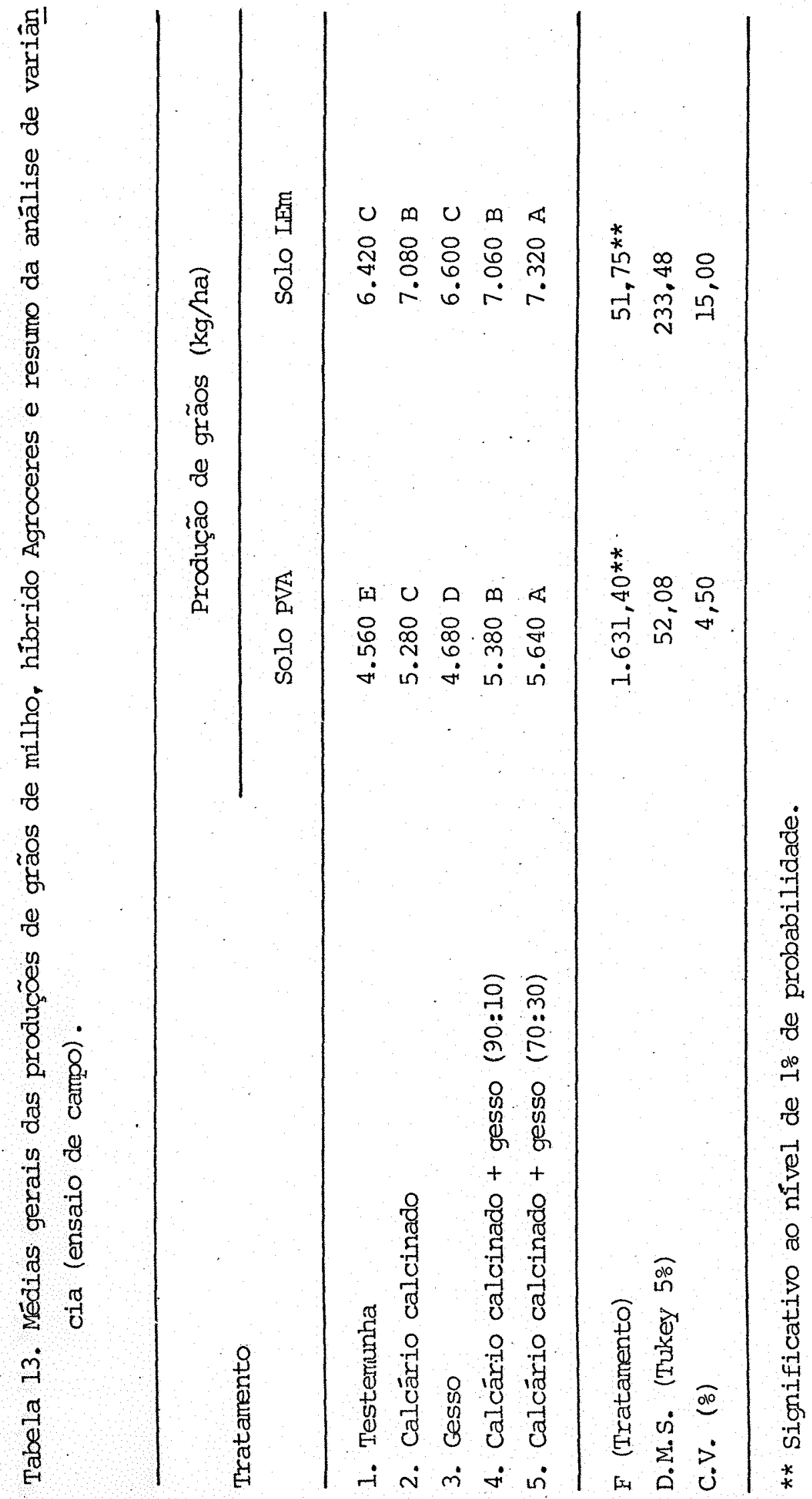




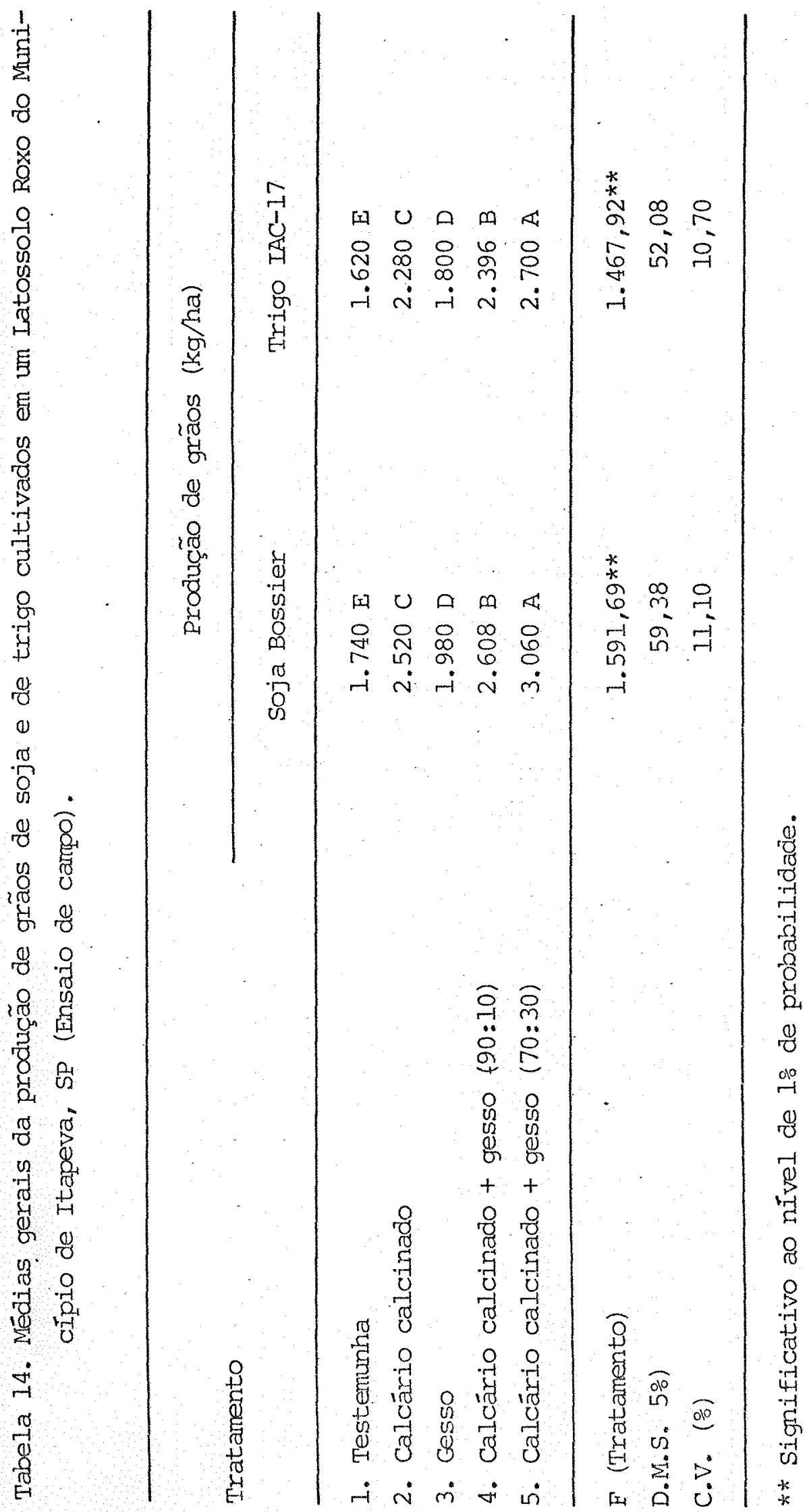




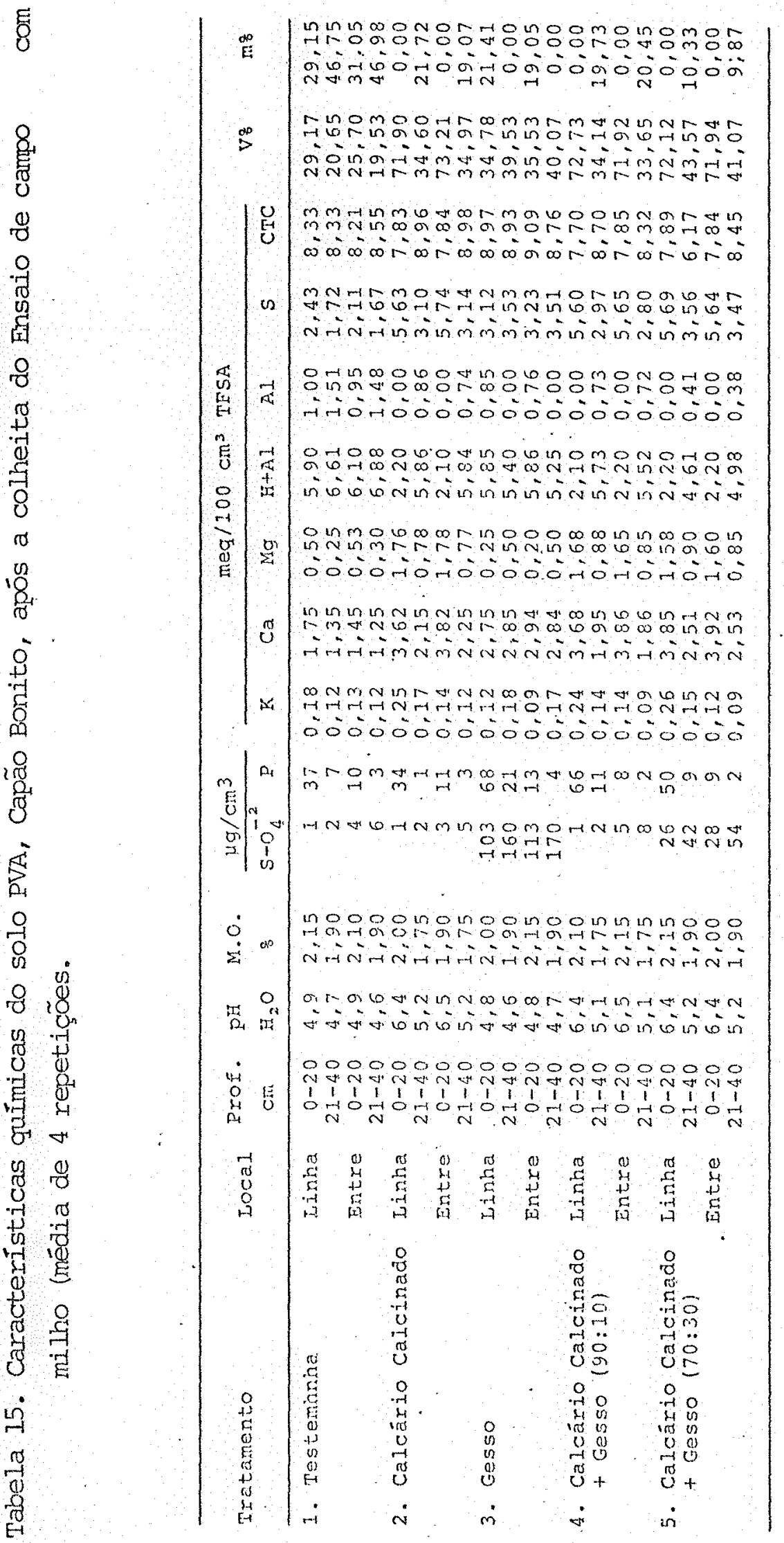




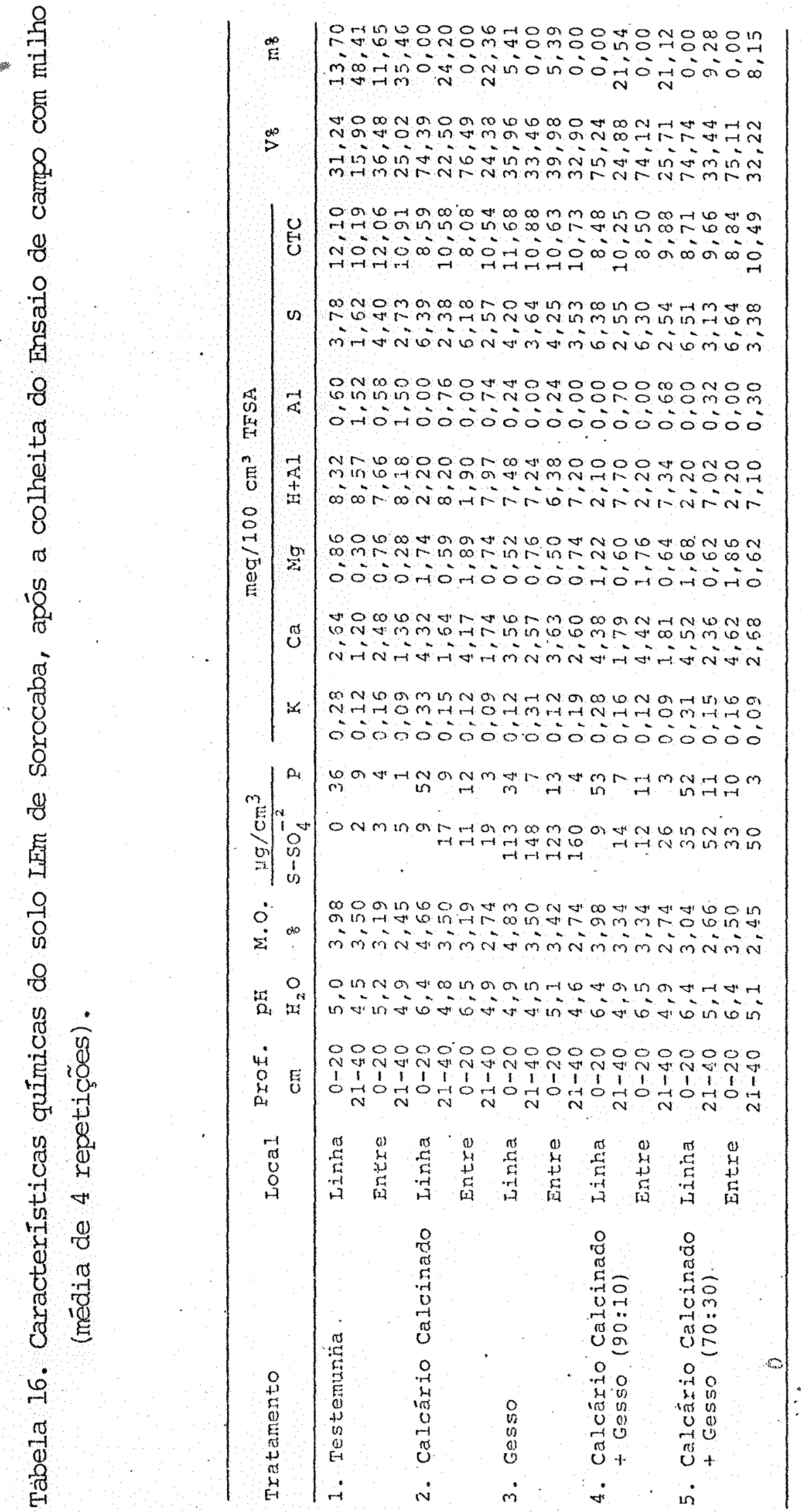



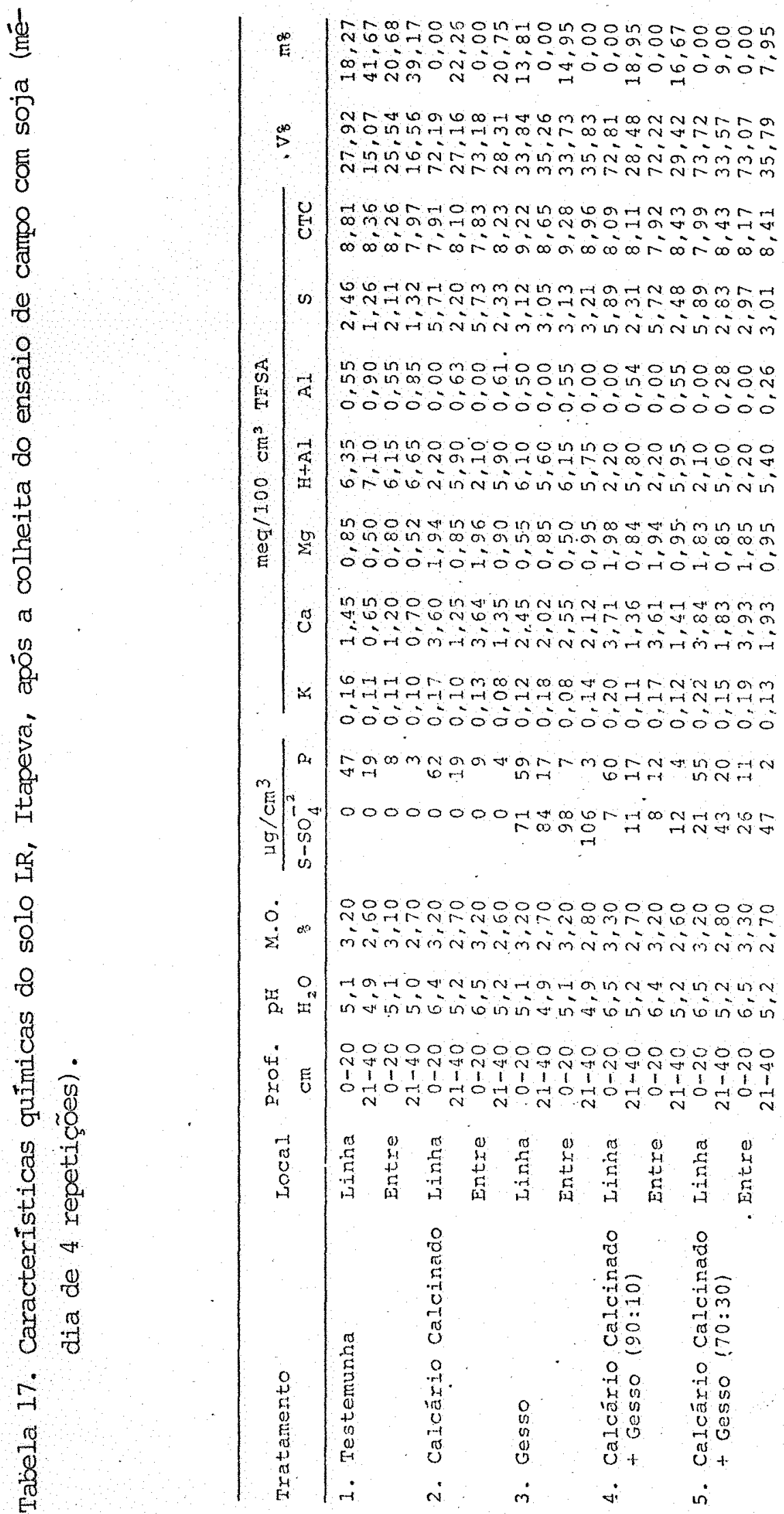


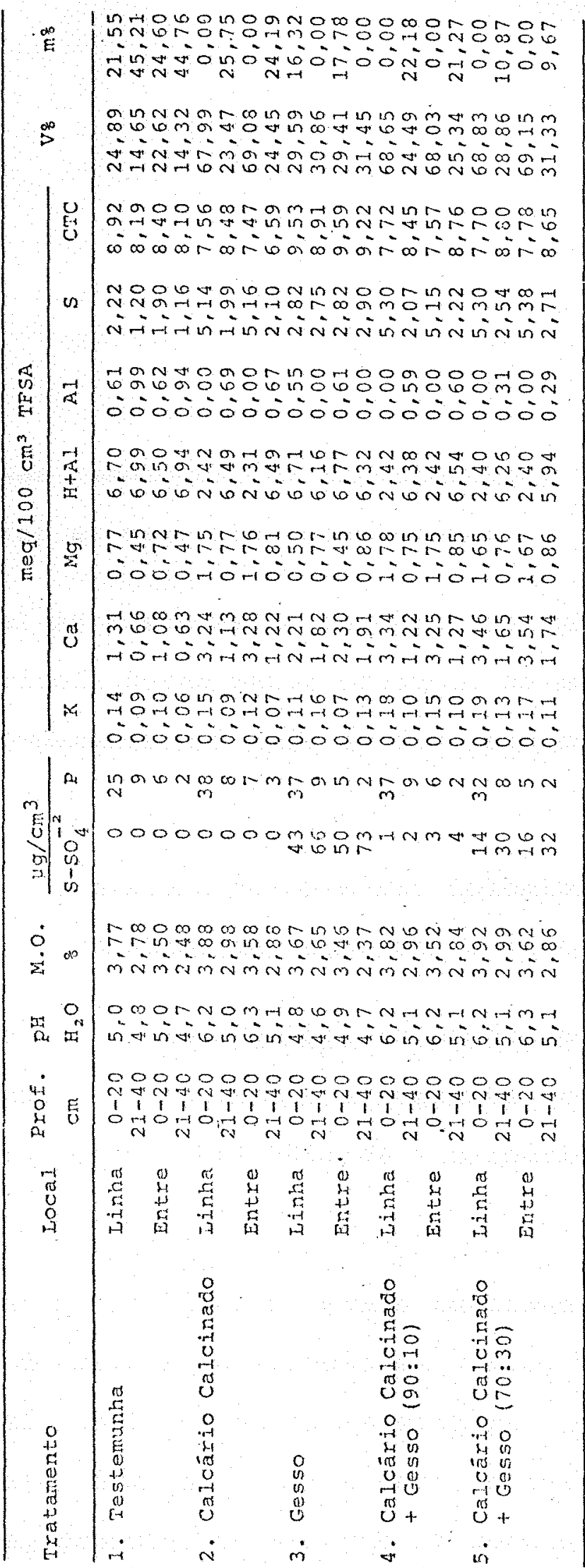




\section{CONCLUSÕES}

Nas condições dos experimentos, os dados obtidos permitem tirar as seguintes conclusões:

a) As misturas de calcário dolomítico calcinado + gesso agrícola deram maior produção de matéria seca ou grãos, quando comparados com cada um dos produtos aplicados separadamente;

b) a mistura de calcário dolomítico calcinaãot gesso (70\%:30\%), demonstrou ser superior à mistura 90\%:10\%;

c) de um modo geral, as produções foram concor dantes, obedecendo os tratamentos a seguinte ordem decrescente: mistura $70 \%: 30 \%>$ mistura $90 \%: 10 \%>$ calcário dolomítico cal cinado > gesso > testemunha;

d) as análises minerais realizadas na parte aê rea das plantas de milho, cultivadas em vasos, mostraram que - calcário dolomítico calcinado e as misturas reduziram as concentrações de Al e Mn na matéria seca; o gesso, quando usa do separadamente, promoveu um aumento na concentração de Mn; 
por outro lado, o calcário dolomítico calcinado e as misturas aumentaram a concentração de $\mathrm{Ca}$, e particularmente de $\mathrm{Mg}$; sempre que o gesso esteve presente houve aumento nos teores de ca e s;

e) nos ensaios de campo, o calcário dolomítico calcinado e as misturas de calcârio calcinado + gesso se comportaram de modo semelhante nas modificações químicas provocadas na superfície; os mesmos tratamentos tiveram efeitos menos acentuados em profundidade $(21-40 \mathrm{~cm})$, sendo a ação da mistura calcário dolomítico calcinado + gesso (70\%:30\%) mais acentuada que a do calcário dolomítico calcinado isolado e que a da mistura com menos gesso; no tratamento em que se empregou somente gesso, houve major lixiviação de $\mathrm{K}^{+}$e $\mathrm{Mg}^{+2}$.

f) o gesso deve ser usado sempre em combina ção com calcārio, de preferência dolomítico calcinado. 


\section{LITERATURA CITADA}

ALVES, H.M.R. e LOPES, A.S. Redução da saturação de alumínio em profundidade pela aplicação superficial de calcário e gesso em Latossolos sob vegetação de cerrado. In: Congres so Brasileiro de Ciência do Solo, 199, Curitiba-PR. Resumos, 1983. p. p2.

BAIIR, G.J. Sulfur in the tropics. Sulfur institute and international Fertilizer Development Center: Muscle Shoals. Alabama, U.S.A. 69p. (Technical Buletin IFDC-T-12), 1979.

CATANI, R.A. e JACINTHO, A.O. Avaliação da Fertilidade do Solo: Método de anāilise. Livroceres Ltàa. Piracicaba$\mathrm{SP}, 1974.57 \mathrm{p}$.

CATANI, R.A. e GALLO, J.R. Avaliação dạ exigência em calcãrio dos solos do Estado de são paujo mediante correlação entre pH e a porcentagem de saturação em bases. Rev. Agr., 30: $49-60, \quad 1955$.

DEMATTE, J.L.I. Solos Arenosos de Baixa Fertilidade: Estratégias de Manejo. Palestra apresentada no V Seminário Agroindustrial "Luiz de Queiroz" - STAB XXIX Semana "Luiz de Queiroz" - 08/10/1986 - Piracicaba-SP, 1986. 
EMBRAPA. Centro de pesquisa Agropecuária dos Cerrados. Re1atório Técnico Anual. Brasília-DF, 1981. 190p.

FREIRE, F.M. ; GUIMARÃES, P.T.G.; VENEGAS, V.H.A. \& MELLES, C. C.A. Calagem, gessagem e adubação do cafeeiro. Belo Hori zonte, EPAMIG/ESALQ/UFMG/UFV. 20p. (Boletim Técnico, II).

GUIMARÃES, P.T.G. ; MELLES, C.R.A.; FREIRE, F.M. \& PONTE, A.M. Influência do gesso e do calcário como corretivos e fornecedores de cálcio e enxofre para o cafeeiro. In: Congresso Brasileiro de Pesquisas Cafeeiras, 10, Poços de Caldas-MG. Anais... s.n.t., 1983. p.164-5.

LOBATO, E. e RITCHEY, K.D. Manejo do solo visando melhorar o aproveitamento da água. In: MARCHETTI, D. e MACHADO, A. D. Coord. V Simpósio sobre o cerrado. Brasilia-DF, Ed. Editerra: $643-671,1980$.

LOPES, A.S. e ALVES, H.M.R. Efeitos da aplícação de corxetivos e fertilizantes na diminuição da toxídez de aluminio em profundidade, em amostras de solos sob vegetação de cerrado em Minas Gerais. In: Congresso Brasileiro de Ciên cias do Solo, 18, Salvador-BA. Programa e Resumos, 1981. p. 96 .

MAtAVotTA, E. Elemento de Nutrição Mineral de plantas. São Faulo, Ed. Agronômica Ceres, 1980. p. 217-251.

MALAVOLTA, E.; GUILHERME, M.R. e LIEM, T.H. Associações fósfogesso-calcário: princípios e aplicações. In: Anais do I seminário sobre o uso do fosfogesso na Agricultura. IBRA FOS/EMBRAPA/PETROFERTIL. Brasí1ia-DF, 177-196, 1986. 
MCCLUNG, A.C. ; FREITAS, L.M.M. de; LOTT, W.L. Analysis of several Brasilian soils in relation to plant responses to sulfur. Soil Science Society of America Proceedings, Madison, $23(3)=221-4,1959$.

OLMOS, J.I.L. Ocorrência de alumínio tóxico nos solos do Brasil, sua ocorrência e distribuição. Ciência e cultura, $28(2): 171-180,1976$.

PAVAN, M.A. O cálcio como nutriente para as culturas: In: SILVA, M.C. de (Coord.). Anais do Seminārio Fósforo, Cálcio, Magnésio, Enxofre e Micronutrientes - situação Atual e Perspectivas na Agricultura. Manah S/A. São Paulo - SP, 1986. $82-86 \mathrm{p}$.

PAVAN, M.A. e VOLKWEISS, S.J. Efeitos do gesso nas relą̧ões solo-planta: princípios. In: Anais do I Seminário sobre - uso do fosfogesso na agricultura. IBRAFOS/EMBRAPA/PETío FERTIL. Brasilia-DF: 107-118, 1986.

PAVAN, M.A. Comportamento do Gesso nos Solos Ãcidos das regiões tropicais e subtropicais. POTAFOS. Informações Agro nômicas, 35, 1986, p.1-2.

PAVAN, M.A.; BINGHAM, F.T. \& PRATT, P.F. Redistribution of exchangeable calcium, magnesium, and aluminum following $1 \underline{i}$ me of gipsum applications to a Brasilian oxisol. Soil Sci. Soc. Amex. J. $48(1): 33-38,1984$.

PONTE, A.M. da; ARANTES, N.E.; GUIMARÃES, P.T.G.; PAULA, M.B. \& SOUSA, R.A. Influēncia do gesso na fertilidade dos solos de cerrado para duas cultivares de soja (Glycine max (L.) Merx.): interação entze níveis de calagem, níveis de gessagem e cultivares: estudo preliminar. s.n.t.a.. s/d. $13 \mathrm{p} .$, mimeografado. 
PONTE, A.M. da; MORAIS, O.P.; SOUZA, M.A.; GUIMARÃES, P.T.G. \& SOUZA, R.A. Interações entre niveis de calagem, niveis de gessagem e duas profundidades de incorporação de corretivos no desenvolvimento e produção de trigo (Triticum aes tivum L. cultivar BR-1146) em solos de cerrado; resulta dos preliminares, s.n.t.b. s/d, Ilp., mimeografado.

PONTE, A.M. da; TANAKA, R.T.; MORAIS, G.P.; BONILLA, J.A.; GUIMARÃES, P.T.G. \& FREIRE, F.M. Influência do gesso na fertilidade de um solo de cerrado para duas cultivares de arroz de sequeiro, interação entre níveis de gesso e niveis de calcário, s.n.t.c., llp., mimeografado.

QUAGGIO, J.A.; MASCARENHAS, H.A.A. e BATAGIIA, O.C. Resposta da soja (Glycine max (L.) Merrill) à aplicação de calcărio em solo Latossolo Roxo Distrófico de Cerrado. II. Efeito residual. In: Congresso Brasileiro de Ciência do Solo, 18, Salvador-BA. Programa e Resumos, 1981. p.46.

QUAGGIO, J.A.; DECHEN, A.R. e RAIJ B. van. Efeitos da aplicação de calcário e gesso sobre a produção de amendoim e lixiviação de bases no solo. R. Bras. Ci. Solo, 6: 1.89$194,1982$.

REEVE, N.G. \& SUMNER, M.E. Amelioration of subsoil acidity in Natal oxisols by leaching of surface applied amendements. Agrochemophysics, 4: 1.-6, 1972 .

RITCHEY, K.D.; SILVA, J.E.; SOUZA, D.M.G. Lixiviação de cálcio e crescimento de raízes em solos de cerrados. In: ConGRESSO BRASILEIRO DE CIENCIAS DO SOLO; 18, Salvador - BA. Programa e Resumos, 1981. p.96. 
ROSOLEM; C.A. e MACHADO, J.R. Efeitos da calagem e gessagem na produção de algodão e na lixiviação de bases em dois Latossolos. R. bras. Ci. Solo, 8: 103-109, 1984.

RAIJ, B. van e QUAGGIO, J.A. Uso eficiente de calcário e gesso na agricultura. In: Anais do Simpósio sobre Fertilizantes na Agricultura Brasileira. EMBRAPA/ANDA/POTAFOS. Brasilia-DF : 323-346, 1984 .

RAIJ, B. van; SILVA, N.M. da; BATAGLIA, O.I.; ZUAGGIO; J.A. ; HIROCE, R.; CANTARELIA, H.; BELLINAZZI Jr., R.; DECHEN, A. R. \& TRANI, P.E. Recomendações de adubação e calagem para o Estado de são paulo. IAC, Campinas-SP, 1985. 107p. (Boletim récnico nọ 100).

RAIJ, B. van \& ZULLO, M.A.T. Métodos de Anālise do Solo. Cam pinas, Instituto Agronômico, 1977. 17p. (Circular, 63).

SANCHEZ, P.A. \& SALINAS, J.G. LOW-imput technology for managing oxisols and ultisols in Tropical America. Advances in Agronomy, New York, 34: 279-406, 1981 .

SIIVA, J.E. e RITCHEY, K.D. Lixiviação de cālcio e crescimen to de raizes em oxisolos de cerrado. In: SIMPOSIO SOBRE O CERRADO, 6, Brasilia-DF, Savanas: Alimento e energia, Bra silia, 1981. (no prelo).

SOUZA, D.M.G. e RITCHEY, K.D. Uso de gesso no solo de cerrado. In: Anais do I Simpösio sobre o uso de fosfogesso na agricultura. IBRAFOS/EMBRAPA/ANDA. Brasilia-DF: 119-114, 1986.

TANAKA, R.T.; PONTE, A.M. da; MORAIS, O.P. de \& CASTILHO, J. A.B. Influência do gesso na fertilidade dos solos de cerra do para duas cultivares de gesso na fertilidade dos solos de cerrado para duas cultivares de arroz (Oryza sativa I.) 
de sequeiro; resultados de $1978 / 79$ e 1979/80. In: PROJETO ARROZ; relatório 78/80. Belo Horizonte, s.ed., p.199-214, 1983.

VITTI, G.C. Acidez e calagem do solo. Rev. Téc. Cient. Citricultura. Laranja, Cordeirópolis, 5: 77-102, 1984.

VITTI, G.C. \& FERREIRA, M.E. Calagem e Gessagem em Culturas. YAMADÁ, T.; RANDO, E.M.; GRILLO, J.M. e SILVA, F.C.M. da (Coord.). Palestra apresentada no curso de atualização em fertilidade do solo. FFALM, POTAFOS e ANDA. Bandeirantes PR, 1986. 195-24lp. Mimeo.

VITTI, G.C. O enxofre na agricultura - situação, perspectivas e sugestões. In: SILVA, M.C. de Coord. Anais do semi nário Fósforo, Cálcio, Magnésio, Enxofre e Micronutrientes - Situação Atual e Perspectivas na Agricultura. Manah S/A, São Paulo, SP, 1986. 98-109p.

VITTI, G.C.; FERREIRA, M.E. e MALAVOLTA, E. Respostas de cul turas anuais e perenes. In: Anais do I seminário sobre o uso do fosfogesso na Agricultura. Brasilia-DF, IBRAFOS / EMBRAPA/PETROFERTIL: $17-43,1986$.

VITTI, G.C. e MALAVOLTA, E. Fosfogesso - uso agricola. In: MALAVOLTA, E. Coord. Seminărio sobre corretivos agrícolas. Fundação Cargill, Campinas-SP: 161-201, 1985. 